(2) Open Access Full Text Article

ORIGINAL RESEARCH

\title{
Glycemic control and antidiabetic drugs in type 2 diabetes mellitus patients with renal complications
}

This article was published in the following Dove Press journal:

Drug Design, Development and Therapy

7 August 2015

Number of times this article has been viewed

\author{
Hasniza Zaman Huri ${ }^{1,2}$ \\ Lay Peng Lim' \\ Soo Kun $\mathrm{Lim}^{3}$ \\ 'Department of Pharmacy, Faculty \\ of Medicine, University of Malaya, \\ ${ }^{2}$ Clinical Investigation Centre, \\ University Malaya Medical Centre, \\ ${ }^{3}$ Renal Unit, Department of Medicine, \\ Faculty of Medicine, University of \\ Malaya, Kuala Lumpur, Malaysia
}

\begin{abstract}
Background: Good glycemic control can delay the progression of kidney diseases in type 2 diabetes mellitus (T2DM) patients with renal complications. To date, the association between antidiabetic agents and glycemic control in this specific patient population is not well established.

Purpose: This study aimed to identify antidiabetic regimens as well as other factors that associated with glycemic control in T2DM patients with different stages of chronic kidney disease (CKD).
\end{abstract}

Patients and methods: This retrospective, cross-sectional study involved 242 T2DM inpatients and outpatients with renal complications from January 2009 to March 2014 and was conducted in a tertiary teaching hospital in Malaysia. Glycated hemoglobin (A1C) was used as main parameter to assess patients' glycemic status. Patients were classified to have good (A1C $<7 \%$ ) or poor glycemic control ( $\mathrm{A} 1 \mathrm{C} \geq 7 \%$ ) based on the recommendations of the American Diabetes Association.

Results: Majority of the patients presented with CKD stage 4 (43.4\%). Approximately 55.4\% of patients were categorized to have poor glycemic control. Insulin (57.9\%) was the most commonly prescribed antidiabetic medication, followed by sulfonylureas $(43 \%)$. Of all antidiabetic regimens, sulfonylureas monotherapy $(P<0.001)$, insulin therapy $(P=0.005)$, and combination of biguanides with insulin $(P=0.038)$ were found to be significantly associated with glycemic control. Other factors including duration of T2DM $(P=0.004)$, comorbidities such as anemia $(P=0.024)$ and retinopathy $(P=0.033)$, concurrent medications such as erythropoietin therapy $(P=0.047), \alpha$-blockers $(P=0.033)$, and antigouts $(P=0.003)$ were also correlated with A1C.

Conclusion: Identification of factors that are associated with glycemic control is important to help in optimization of glucose control in T2DM patients with renal complication.

Keywords: glycemic control, type 2 diabetes, antidiabetic regimens, renal complications

\section{Introduction}

Diabetes mellitus (DM) has emerged as one of the most prevalent chronic diseases worldwide. In Malaysia, a recent study reported that the overall prevalence of DM among Malaysians was $22.9 \%$ in 2013 , with $12.1 \%$ of those $22.9 \%$ newly diagnosed. ${ }^{1}$

Among several types of DM, type 2 diabetes mellitus (T2DM) accounts for $90 \%-95 \%$ of the diabetes cases. ${ }^{2}$ T2DM is usually accompanied by macrovascular complications such as coronary artery disease, peripheral artery disease, and stroke as well as microvascular complications such as diabetic nephropathy, retinopathy, and neuropathy. ${ }^{3}$ Microvascular complications, especially renal diseases, have shown extremely high prevalence which was approximately $92 \%$ among T2DM patients in a study conducted by Abougalambou et $\mathrm{al}^{4}$ at a teaching hospital in Malaysia.

There are two main types of renal complications which are commonly diagnosed in T2DM patients, namely chronic kidney disease (CKD) and diabetes nephropathy. According to the National Kidney Foundation (NKF) Kidney Disease Outcomes
Correspondence: Hasniza Zaman Huri Department of Pharmacy, Faculty of Medicine, University of Malaya, Kuala Lumpur, 50603, Malaysia

Tel +60379676659

Fax +60379674964

Email hasnizazh@um.edu.my (c) (i) (9) 2015 Huri et al. This work is published by Dove Medical Press Limited, and licensed under Creative Commons Attribution - Non Commercial (unported, v3.0) License. The full terms of the License are available at http://creativecommons.org/licenses/by-nd/3.0/. Non-commercial uses of the work are permitted without any further permission from Dove Medical Press Limited, provided the work is properly attributed. Permissions beyond the scope of the License are administered by Dove Medical Press Limited. Information on how to request permission may be found at: http://www.dovepress.com/permissions.php 
Quality Initiative (KDOQI), ${ }^{5} \mathrm{CKD}$ is termed as "either kidney damage with or without reduction in estimated glomerular filtration rate (eGFR), or a GFR of less than $60 \mathrm{~mL} / \mathrm{min} / 1.73 \mathrm{~m}^{2}$, lasting for 3 months or more". Meanwhile, diabetic nephropathy is the kidney disease caused by diabetes that exhibits albuminuria as the earliest clinical manifestation. ${ }^{6}$ Diabetic nephropathy affects up to $40 \%$ of diabetic patients and it is currently known as the primary cause of end-stage renal failure (ESRF). ${ }^{7}$ In 2007, 57\% of new patients who receive dialysis therapy in Malaysia were contributed by diabetes nephropathy. ${ }^{8}$

As the number of diabetes patients with ESRF is rising at an alarming rate, optimizing glycemic control is an important approach to delay the progression of renal diseases among T2DM patients. Use of antidiabetic medications in T2DM patients with renal complications, including insulin, oral antidiabetic drugs (OADs), such as sulfonylureas (SUs), thiazolidinediones, metformin, and other OADs as well as antidiabetic combination was discovered in previous studies. By using glycated hemoglobin (A1C) level in the assessment of glycemic control as suggested by the American Diabetes Association ${ }^{7}$, United Kingdom Prospective Diabetes Study, ${ }^{9}$ and Shichiri et $\mathrm{al}^{10}$ have proven that good glycemic control can reduce the risk of developing albuminuria and slow the progression of renal diseases in T2DM patients. Duckworth et $\mathrm{al}^{11}$ and Patel et $\mathrm{al}^{12}$ also reported that intensive glucose control had resulted in a significant reduction in worsening of nephropathy in patients with T2DM.

Currently, there are limited studies demonstrating the renoprotective effects of one antidiabetic agent over another in preventing the deterioration of renal diseases. ${ }^{13}$ Therefore, this retrospective study was conducted to examine antidiabetic regimens that associated with glycemic control. This study also investigated the association of glycemic control with other factors such as patients' demographic and clinical characteristics, comorbidities, and concomitant drug treatments in the study population. The aim of this study is to identify antidiabetic regimens and other factors that associated with glycemic control in T2DM patients with different stages of CKD.

\section{Patients and methods Study design and setting}

This was a retrospective, cross-sectional study conducted in University of Malaya Medical Centre (UMMC), a premier teaching hospital in Malaysia with 1,000 beds. This study was conducted in accordance with the Declaration of Helsinki and was approved by the Medical Ethics Committee of UMMC (reference number: 1031.52). The Medical Ethics Committee of UMMC waived the need for written informed consent from the participants.

\section{Study population, sampling frame, and sampling size}

The study population consisted of T2DM inpatients and outpatients with renal complications who had received at least one antidiabetic medication in the UMMC. The sampling frame for this study was from January 1, 2009 to March 31, 2014. In this study, the required sampling size was calculated using Epi Info ${ }^{\mathrm{TM}}$ version 7.0 (Centers for Disease Control and Prevention, Atlanta, GA, USA). The level of significance, $\alpha$, was set as 0.05 , and the desired power of the study, $1-\beta$, was $80 \%$. Assuming that the expected proportion of T2DM patients on medications was $22.9 \%$ and confidence limit was $5 \%$, the minimum sample size calculated was 116 .

\section{Inclusion and exclusion criteria}

The inclusion criteria for this study were: adult patients who aged 18 years old and above; T2DM patients who were diagnosed with CKD and/or diabetes nephropathy; patients who had received at least one antidiabetic medication for at least 3 months with their A1C measurements available thereafter (Ministry of Health Malaysia, ${ }^{14}$ Patel et al ${ }^{12}$ and UKPDS Group ${ }^{9}$ ).

The exclusion criteria for this study were: patients with other types of DM; patients who were not received any antidiabetic medication or those solely on diet controls for T2DM; patients who were not compliant to their antidiabetic medications.

\section{Study procedure}

First, the registration numbers of patients who fulfilled the criteria of International Classification of Diseases, Tenth Edition (ICD-10) coding system for T2DM (E11.0-E11.8) from January 1, 2009 to December 31, 2013 were identified using Hospital Information System. At the same time, the registration numbers of patients who came for follow-up in the Renal Clinic, UMMC, on every Monday from January 2014 to March 2014 were obtained. After that, convenient sampling was done to select the samples of population. By using respective patients' registration numbers, patients' medical records were traced and retrieved from Medical Record Office. Patients were assessed based on all the inclusion and exclusion criteria, so that only eligible patients were included in the study.

Data that were collected from patients' medical records included: 
Table I Definition of terms used in study

\begin{tabular}{|c|c|c|}
\hline Terms & Definition & Sources \\
\hline Elderly & Older adult aged 65 years old and above. & Kirkman et al ${ }^{16}$ \\
\hline BMI classification & $\begin{array}{l}\text { BMI is categorized according to Malaysian population into underweight }\left(<18.5 \mathrm{~kg} / \mathrm{m}^{2}\right) \text {, } \\
\text { normal }\left(18.5-22.9 \mathrm{~kg} / \mathrm{m}^{2}\right) \text {, pre-obese }\left(23.0-27.4 \mathrm{~kg} / \mathrm{m}^{2}\right) \text {, and obese }\left(\geq 27.5 \mathrm{~kg} / \mathrm{m}^{2}\right) \text {. }\end{array}$ & Ministry of Health Malaysia ${ }^{17}$ \\
\hline Glycemic control & $\begin{array}{l}\text { Good glycemic control refers to those who are able to achieve targeted AIC level } \\
\text { of }<7 \% \text {, regardless of presence of kidney disease. }\end{array}$ & $\begin{array}{l}\text { American Diabetes Association, }{ }^{7} \text { KDIGO } \\
\text { CKD Work Group, }{ }^{15} \text { Ministry of Health } \\
\text { Malaysia, }{ }^{18} \text { National Kidney Foundation }{ }^{19}\end{array}$ \\
\hline Polypharmacy & Concurrent use of five or more different medications in a patient. & Nobili et $a^{20}$ \\
\hline Comorbidities & $\begin{array}{l}\text { Presence of two or more coexisting medical conditions or disease processes that } \\
\text { are additional to an initial diagnosis. }\end{array}$ & Mosby’s Medical Dictionary ${ }^{21}$ \\
\hline $\begin{array}{l}\text { Diabetic } \\
\text { retinopathy (DR) }\end{array}$ & $\begin{array}{l}\text { Any noninflammatory disease of the retina associated with diabetes mellitus, } \\
\text { including proliferative DR and nonproliferative DR. }\end{array}$ & $\begin{array}{l}\text { Dorland's Illustrated Medical } \\
\text { Dictionary }\end{array}$ \\
\hline $\begin{array}{l}\text { Diabetic } \\
\text { neuropathy }\end{array}$ & $\begin{array}{l}\text { Presence of symptoms and/or signs of peripheral nerve dysfunction in diabetic } \\
\text { patients after the exclusion of other causes, which includes sensory, autonomic, focal } \\
\text { and multifocal neuropathy. }\end{array}$ & Boulton et $\mathrm{al}^{23}$ \\
\hline Anemia & Hemoglobin level of $<13.0 \mathrm{~g} / \mathrm{dL}$ in men and $<12.0 \mathrm{~g} / \mathrm{dL}$ in women. & National Kidney Foundation ${ }^{24}$ \\
\hline
\end{tabular}

Abbreviations: BMI, body mass index; AIC, glycated hemoglobin.

- Patients' demographic information such as age, sex, ethnicity, weight, height, body mass index (BMI), and social history. BMI was calculated based on the following formula: BMI $=$ Weight $(\mathrm{kg}) /($ height $\times$ height $)\left(\mathrm{m}^{2}\right)$

- Patient's clinical characteristics, including duration of T2DM since diagnosis, stages of CKD, and presence of albuminuria or proteinuria. eGFR of patients was calculated by Modification of Diet in Renal Disease (MDRD) Study Equation using patients' age, sex, race, and serum creatinine level, as suggested by nephrologist in the UMMC. Patients were then classified into different stages of CKD based on their eGFR according to the Kidney Disease: Improving Global Outcomes (KDIGO) Clinical Practice Guideline 2012.15

- Patient's comorbidities, referring to coexisting diseases or medical conditions.

- Antidiabetic medications and other concurrent medications received by patients.

- Relevant laboratory results such as A1C, fasting blood glucose (FBG), and hemoglobin levels.

Definition of terms used in this study are summarized in Table $1 .{ }^{16-24}$

\section{Statistical techniques}

All the data extracted in this study were pooled and analyzed using the IBM Statistical Package for the Social Science (SPSS) Statistics version 20.0 (IBM Corporation, Armonk, NY, USA). Kolmogorov-Smirnov test was used to test for normality of continuous data such as age, BMI, A1C, and FBG levels. Normally distributed data were expressed as mean \pm standard deviation, whereas data which were not normally distributed were expressed as median (interquartile range). On the other hand, categorical data such as sex, age group, ethnicity, stages of CKD, and classes of antidiabetic drugs were presented as percentage.

Chi-square test of independence was used to examine the association between two categorical variables. The results were known to be statistically significant when the $P$-value was less than 0.05 . The following conditions were applied while using chi-square test of independence:

- Continuity correction was used when less than $20 \%$ of the cells had an expected count of less than 5 cells in a $2 \times 2$ table.

- Pearson chi-square test was used when less than $20 \%$ of the cells had an expected count of less than 5 cells in table greater than $2 \times 2$.

- Fisher's exact test was used when at least $20 \%$ of the cells had an expected count of less than 5 .

All the findings were summarized and presented in the form of frequency tables and graphs. Overview of the methodology is shown in Figure 1.

\section{Results \\ Study subjects selection}

There were a total of 1,929 patients identified from the Hospital Information System based on ICD-10 code for T2DM with renal complications, and from renal clinics for patients who came for follow-up. Application was made for retrieval of 625 patients' medical records from the Medical Record Office, but only 553 medical records were successfully retrieved. Out of 553 patients' medical records, 311 patients were excluded from study because they did not fulfill the inclusion criteria. Therefore, the final total number of eligible patients who were included in the study was 242 . The selection of study subjects is illustrated in Figure 2. 


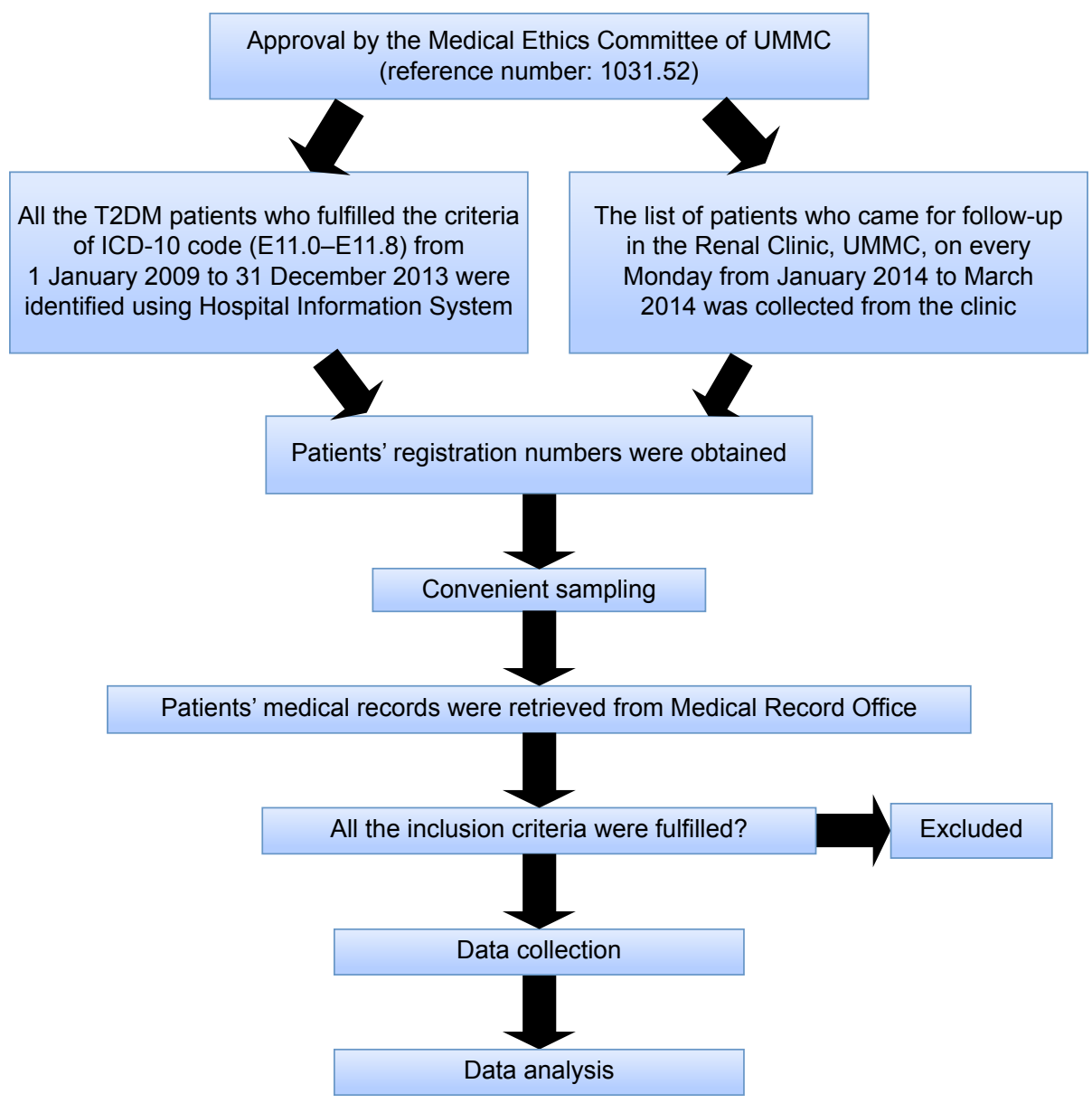

Figure I Overview of methodology.

Abbreviations: T2DM, type 2 diabetes mellitus; UMMC, University of Malaya Medical Centre; ICD-I0, International Classification of Diseases, Tenth Edition.

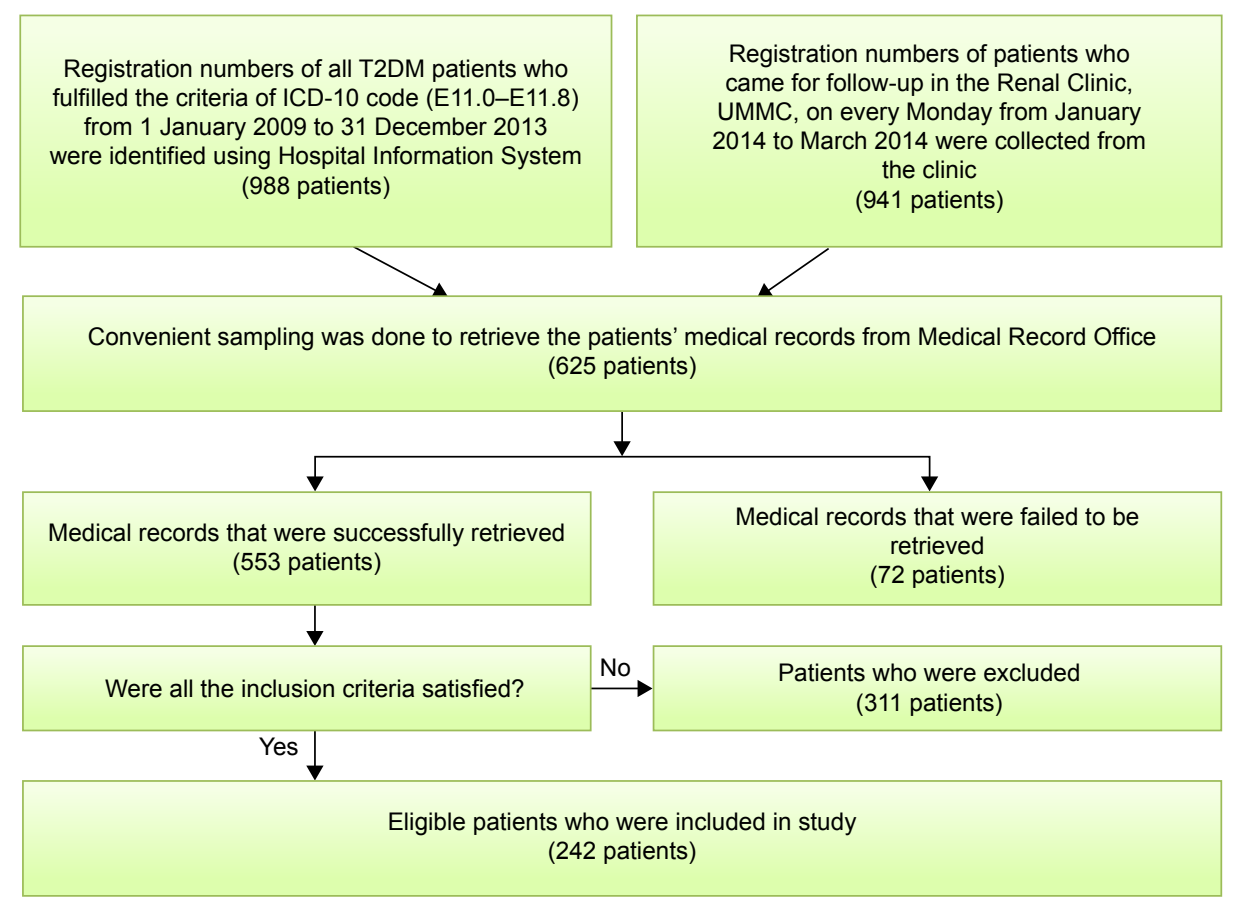

Figure 2 Flowchart of study subjects' selection.

Abbreviations: T2DM, type 2 diabetes mellitus; UMMC, University of Malaya Medical Centre; ICD-I0, International Classification of Diseases, Tenth Edition. 


\section{Demographic characteristics}

A total of 242 T2DM patients with renal complications were included in this study. The study population was made up of approximately equal proportions of female and male patients, with a difference of less than $3 \%$. Age of patients was found to be normally distributed when tested with the Kolmogorov-Smirnov test of normality. The mean \pm standard deviation of patients' age was $65.9 \pm 11.0$ years old, with the minimum and maximum age of 35 and 91 years old, respectively. Demographic characteristics of patients are shown in Table 2.

\section{Clinical characteristics}

Clinical characteristics of patients are described in Table 3. Information on duration of T2DM was available only for 223 patients. The main parameter of glycemic control, A1C, was not normally distributed with median of $7.2 \%$ (interquartile range 6.1-8.4\%); median FBG level was $7.5 \mathrm{mmol} / \mathrm{L}$ (interquartile range $5.7-9.7 \mathrm{mmol} / \mathrm{L}$ ).

In the study population, median eGFR was $25 \mathrm{~mL} / \mathrm{min} /$ $1.73 \mathrm{~m}^{2}$ (interquartile range $16-34 \mathrm{~mL} / \mathrm{min} / 1.73 \mathrm{~m}^{2}$ ). Albuminuria and proteinuria tests were only conducted in 44 and 113 patients, respectively. Results of urine tests revealed that approximately three quarters of patients who had undergone

Table 2 Demographic characteristics of patients ( $N=242)$

\begin{tabular}{ll}
\hline Demographic characteristics & Number of patients (\%) \\
\hline Sex & $118(48.8)$ \\
Male & $124(5 \mathrm{I} .2)$ \\
Female & \\
Age & $106(43.8)$ \\
Non-elderly & $136(56.2)$ \\
Elderly & \\
Ethnicity & $98(40.5)$ \\
Malay & $83(34.3)$ \\
Chinese & $60(24.8)$ \\
India & $1(0.4)$ \\
Others & $2(0.8)$ \\
Body mass index $(\mathrm{BMI}) *$ & $23(9.5)$ \\
Underweight $\left(<\mathrm{I} 8.5 \mathrm{~kg} / \mathrm{m}^{2}\right)$ & $61(25.2)$ \\
Normal $\left(18.5-22.9 \mathrm{~kg} / \mathrm{m}^{2}\right)$ & $67(27.7)$ \\
Pre-obese $\left(23.0-27.4 \mathrm{~kg} / \mathrm{m}^{2}\right)$ & $89(36.8)$ \\
Obese $\left(\geq 27.5 \mathrm{~kg} / \mathrm{m}^{2}\right)$ & $16(6.6)$ \\
Unknown & $131(54.1)$ \\
Smoking status & $39(16.1)$ \\
Yes & $56(23.2)$ \\
No & $59(24.4)$ \\
Ex-smoker & $54(22.3)$ \\
Unknown & $129(53.3)$ \\
Family history of T2DM &
\end{tabular}

Note: $* \mathrm{BMI}=$ Weight $(\mathrm{kg}) /($ height $\times$ height $)\left(\mathrm{m}^{2}\right)$.

Abbreviation: T2DM, type 2 diabetes mellitus.
Table 3 Clinical characteristics of patients

\begin{tabular}{|c|c|c|}
\hline Clinical characteristics & $\mathbf{N}$ & $\begin{array}{l}\text { Number of } \\
\text { patients (\%) }\end{array}$ \\
\hline Duration of T2DM (years) & 242 & \\
\hline$\leq 10$ & & $67(27.7)$ \\
\hline $10-20$ & & $82(33.9)$ \\
\hline $20-30$ & & $5 I(2 I .1)$ \\
\hline$\geq 30$ & & $23(9.5)$ \\
\hline Unknown & & $19(7.8)$ \\
\hline $\mathrm{AIC}(\%)$ & 242 & \\
\hline$<7$ & & $108(44.6)$ \\
\hline$\geq 7$ & & $134(55.4)$ \\
\hline Fasting blood glucose & 208 & \\
\hline Within targeted range (3.9-7.2 mmol/L) & & $90(43.3)$ \\
\hline $\begin{array}{l}\text { Not within targeted range } \\
(<3.9 \text { or }>7.2 \mathrm{mmol} / \mathrm{L})\end{array}$ & & $118(56.7)$ \\
\hline Stages of CKD & 242 & \\
\hline Stage I $\left(e G F R \geq 90 \mathrm{~mL} / \mathrm{min} / 1.73 \mathrm{~m}^{2}\right)$ & & $2(0.8)$ \\
\hline Stage 2 (eGFR 60-89 mL/min/l.73 m²) & & $3(1.2)$ \\
\hline Stage 3a (eGFR $\left.45-59 \mathrm{~mL} / \mathrm{min} / 1.73 \mathrm{~m}^{2}\right)$ & & $13(5.4)$ \\
\hline Stage 3b (eGFR 30-44 mL/min/l.73 m²) & & $70(28.9)$ \\
\hline Stage 4 (eGFR I5-29 mL/min/l.73 m²) & & $105(43.4)$ \\
\hline Stage $5\left(\mathrm{eGFR}<15 \mathrm{~mL} / \mathrm{min} / 1.73 \mathrm{~m}^{2}\right)$ & & $49(20.3)$ \\
\hline Albuminuria & 44 & \\
\hline \multicolumn{3}{|l|}{ Normal to mildly increased } \\
\hline$(\mathrm{UACR}<3 \mathrm{mg} / \mathrm{mmol})$ & & $2(4.5)$ \\
\hline \multicolumn{3}{|l|}{ Moderately increased } \\
\hline (UACR 3-30 mg/mmol) & & $8(18.2)$ \\
\hline Severely increased (UACR $>30 \mathrm{mg} / \mathrm{mmol})$ & & $34(77.3)$ \\
\hline Proteinuria & 113 & \\
\hline \multicolumn{3}{|l|}{ Normal to mildly increased } \\
\hline$(\mathrm{UPCR}<15 \mathrm{mg} / \mathrm{mmol})$ & & $5(4.4)$ \\
\hline \multicolumn{3}{|l|}{ Moderately increased } \\
\hline (UPCR I5-50 mg/mmol) & & $26(23.0)$ \\
\hline Severely increased (UPCR >50 mg/mmol) & & $82(72.6)$ \\
\hline Polypharmacy & 242 & \\
\hline Yes & & $226(93.4)$ \\
\hline No & & $16(6.6)$ \\
\hline
\end{tabular}

Abbreviations: CKD, chronic kidney disease; eGFR, estimated glomerular filtration rate; AIC, glycated hemoglobin; T2DM, type 2 diabetes mellitus; UACR, urinary albumin-to-creatinine ratio; UPCR, urinary protein-to-creatinine ratio.

any of the tests have either severely increased albuminuria or proteinuria.

Among 242 patients, more than $90 \%$ of them practiced polypharmacy, indicating concurrent use of five or more medications. The median number of medications received by patients is 8.0 (interquartile range $6.0-10.0$ ) drugs.

In the study population, 235 patients $(97.1 \%)$ presented with more than one comorbidity, whereas only one patient $(0.4 \%)$ had no other concomitant disease. Figure 3 summarizes the comorbidities of T2DM patients with renal complications. Other comorbidities include hypothyroidism (number of patients, $n=6)$, osteoarthritis $(n=6)$, hepatitis $(n=5)$, bronchial asthma $(n=5)$, atrial fibrillation $(n=5)$, peripheral vascular disease $(n=2)$, sleep apnea $(n=2)$, Alzheimer's disease $(n=2)$, schizophrenia $(n=2)$, hyperthyroidism $(n=2)$, 


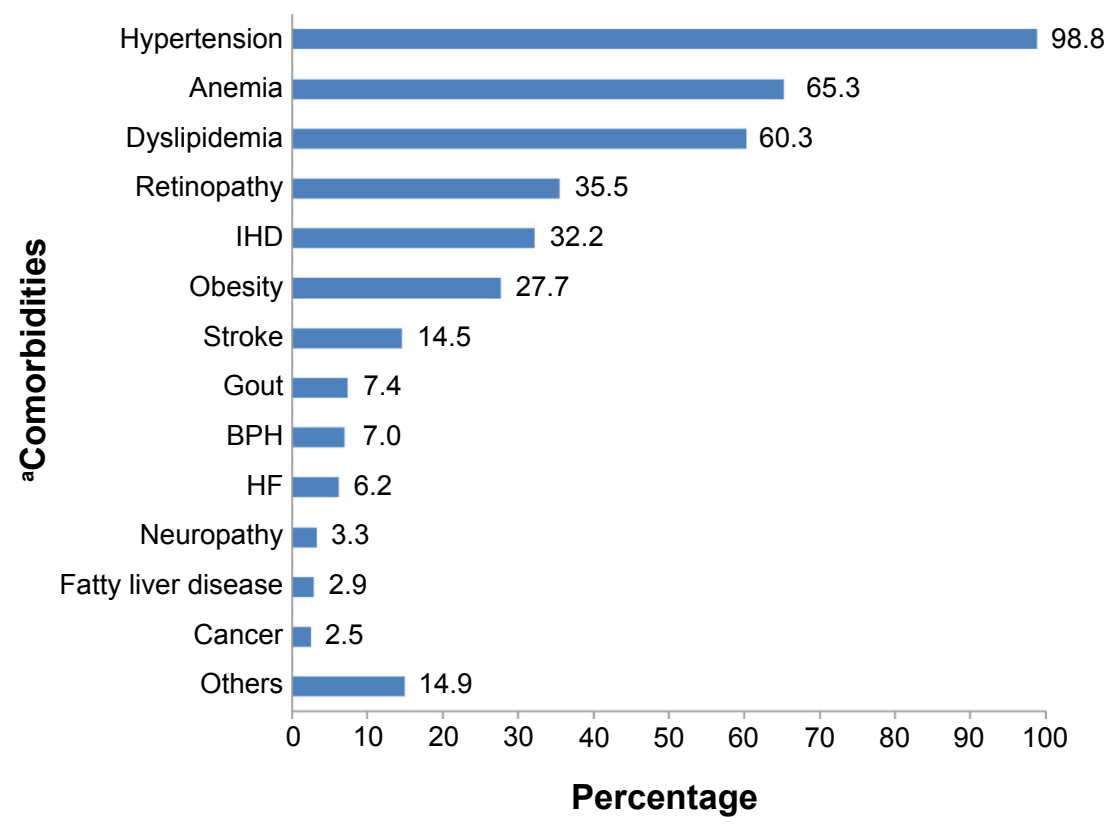

Figure 3 Comorbidities of T2DM patients with renal complications $(\mathrm{N}=242)$.

Note: ${ }^{a} \mathrm{~A}$ patient may have more than one comorbidity.

Abbreviations: BPH, benign prostate hyperplasia; HF, heart failure; IHD, ischemic heart disease; T2DM, type 2 diabetes mellitus.

epilepsy ( $n=1)$, and erectile dysfunction $(n=1)$. The majority of patients were prescribed with either two (47.1\%) or single antidiabetic (44.2\%) medications. Figure 4 shows five classes of antidiabetic medications used in patients.

Table 4 displays association of antidiabetic agents used and glycemic control in T2DM patients according to stages of CKD. Biguanides was the only class of antidiabetic drug that was found to have a significant association with stages of CKD $(P<0.001)$.

\section{Biguanides}

Of 242 patients, only 41 were prescribed with biguanides for glycemic control. The dosing regimens of biguanides are shown in Figure 5. Metformin $850 \mathrm{mg}$ twice daily (BD) and metformin $500 \mathrm{mg} \mathrm{BD}$ are the top-two most frequently prescribed regimens.

\section{Sulfonylureas}

Approximately three quarters (76\%) of patients on SUs were given gliclazide-modified-release (MR) form, followed by gliclazide and glipizide with a similar percentage of $11.5 \%$. There was only one patient who had received glibenclamide (1\%) among the patients on SUs (Figure 6).

\section{$\alpha$-Glucosidase inhibitors}

Only six patients were given $\alpha$-glucosidase inhibitors as antidiabetic agent in the management of T2DM; acarbose $100 \mathrm{mg}$ thrice daily, acarbose $50 \mathrm{mg}$ thrice daily, and

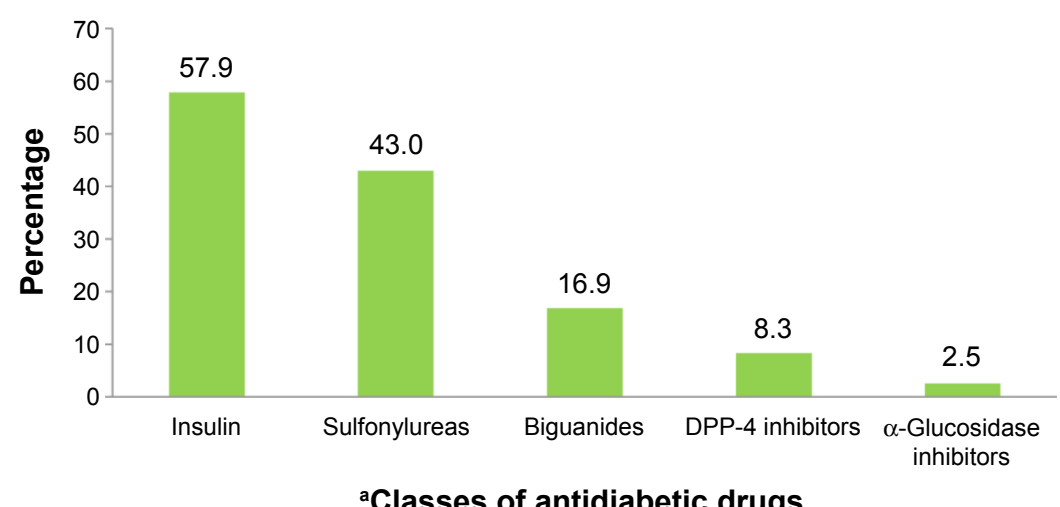

Figure 4 Classes of antidiabetic drugs used in T2DM patients with renal complications.

Note: ${ }^{a} A$ patient may receive more than one class of antidiabetic drugs.

Abbreviations: T2DM, type 2 diabetes mellitus; DPP-4, dipeptidyl peptidase-4. 
Table 4 Antidiabetic agents and glycemic control in T2DM patients with different stages of CKD (N=242)

\begin{tabular}{|c|c|c|c|c|c|c|c|c|}
\hline & \multirow[t]{2}{*}{$\mathbf{N}^{\mathrm{a}}(\%)$} & \multicolumn{7}{|c|}{ Number of patients (\%) } \\
\hline & & $\begin{array}{l}\text { Stage I } \\
(n=2)\end{array}$ & $\begin{array}{l}\text { Stage } 2 \\
(n=3)\end{array}$ & $\begin{array}{l}\text { Stage 3a } \\
(n=13)\end{array}$ & $\begin{array}{l}\text { Stage 3b } \\
(\mathrm{n}=70)\end{array}$ & $\begin{array}{l}\text { Stage } 4 \\
(n=105)\end{array}$ & $\begin{array}{l}\text { Stage } 5 \\
(n=49)\end{array}$ & $P$-value \\
\hline \multicolumn{9}{|c|}{ Classes of antidiabetic drugs } \\
\hline Biguanides & & & & & & & & $<0.00 \mathrm{I}^{\mathrm{b}, *}$ \\
\hline Yes & $4 \mid(16.9)$ & $2(4.9)$ & I (2.4) & $10(24.4)$ & $18(43.9)$ & $10(24.4)$ & $0(0.0)$ & \\
\hline No & $201(83.1)$ & $0(0.0)$ & $2(1.0)$ & $3(1.5)$ & $52(25.9)$ & $95(47.3)$ & $49(24.4)$ & \\
\hline Sulfonylureas & & & & & & & & $0.230^{\mathrm{b}}$ \\
\hline Yes & $104(43.0)$ & $0(0.0)$ & $2(1.9)$ & $6(5.8)$ & $35(33.7)$ & $46(44.2)$ & $15(14.4)$ & \\
\hline No & I $38(57.0)$ & $2(1.4)$ & $\mathrm{I}(0.7)$ & $7(5.1)$ & $35(25.4)$ & $59(42.8)$ & $34(24.6)$ & \\
\hline$\alpha$-Glucosidase inhibitors & & & & & & & & $0.853^{\mathrm{b}}$ \\
\hline Yes & $6(2.5)$ & $0(0.0)$ & $0(0.0)$ & $0(0.0)$ & $2(33.3)$ & $2(33.3)$ & $2(33.3)$ & \\
\hline No & $236(97.5)$ & $2(0.8)$ & $3(1.3)$ & $13(5.5)$ & $68(28.8)$ & $103(43.6)$ & $47(19.9)$ & \\
\hline DPP-4 inhibitors & & & & & & & & $0.890^{\mathrm{b}}$ \\
\hline Yes & $20(8.3)$ & $0(0.0)$ & $0(0.0)$ & I (5.0) & $7(35.0)$ & $7(35.0)$ & $5(25.0)$ & \\
\hline No & 222 (91.7) & $2(0.9)$ & $3(1.4)$ & $12(5.4)$ & $63(28.4)$ & $98(44.1)$ & $44(19.8)$ & \\
\hline Insulin & & & & & & & & $0.409^{b}$ \\
\hline Yes & I 40 (57.9) & $2(1.4)$ & $\mathrm{I}(0.7)$ & $8(5.7)$ & $36(25.7)$ & $60(42.9)$ & $33(23.6)$ & \\
\hline No & $102(42.1)$ & $0(0.0)$ & $2(2.0)$ & $5(4.9)$ & $34(33.3)$ & $45(44.1)$ & $16(15.7)$ & \\
\hline \multicolumn{9}{|l|}{ Glycemic control } \\
\hline $\operatorname{AIC}(\%)$ & & & & & & & & $0.143^{b}$ \\
\hline$<7$ & $108(44.6)$ & $0(0.0)$ & $2(1.9)$ & $3(2.8)$ & $27(25.0)$ & $49(45.4)$ & $27(25.0)$ & \\
\hline$\geq 7$ & I 34 (55.4) & $2(1.5)$ & $\mathrm{I}(0.7)$ & $10(7.5)$ & $43(32.1)$ & $56(4 I .8)$ & $22(16.4)$ & \\
\hline
\end{tabular}

Notes: ${ }^{a} \mathrm{~A}$ patient may receive more than one antidiabetic agent; ${ }^{b}$ computed by Fisher's exact test; *statistically significant $(P<0.05)$.

Abbreviations: CKD, chronic kidney disease; T2DM, type 2 diabetes mellitus; DPP-4, dipeptidyl peptidase-4; AIC, glycated hemoglobin.

acarbose $50 \mathrm{mg}$ BD were the dosage regimens used in these patients.

\section{DPP-4 inhibitors}

As for dipeptidyl peptidase-4 (DPP-4) inhibitors, more than $80 \%$ of patients were on sitagliptin with different doses of 25,50 , or $100 \mathrm{mg}$ once daily, whereas only one patient was on saxagliptin, linagliptin, and vildagliptin for each of these drugs. The dosage regimens of DPP-4 inhibitors are shown in Figure 7.
Insulin

As shown in Figure 8, a combination of short-acting insulin Actrapid and long-acting insulin Insulatard was the most favorable insulin regimens that commonly prescribed to T2DM patients, with a percentage of approximately $50 \%$. This was followed by Mixtard, a premixed insulin that consists of soluble human insulin and isophane human insulin. Other insulin regimens were only used by less than $6 \%$ of patients each.

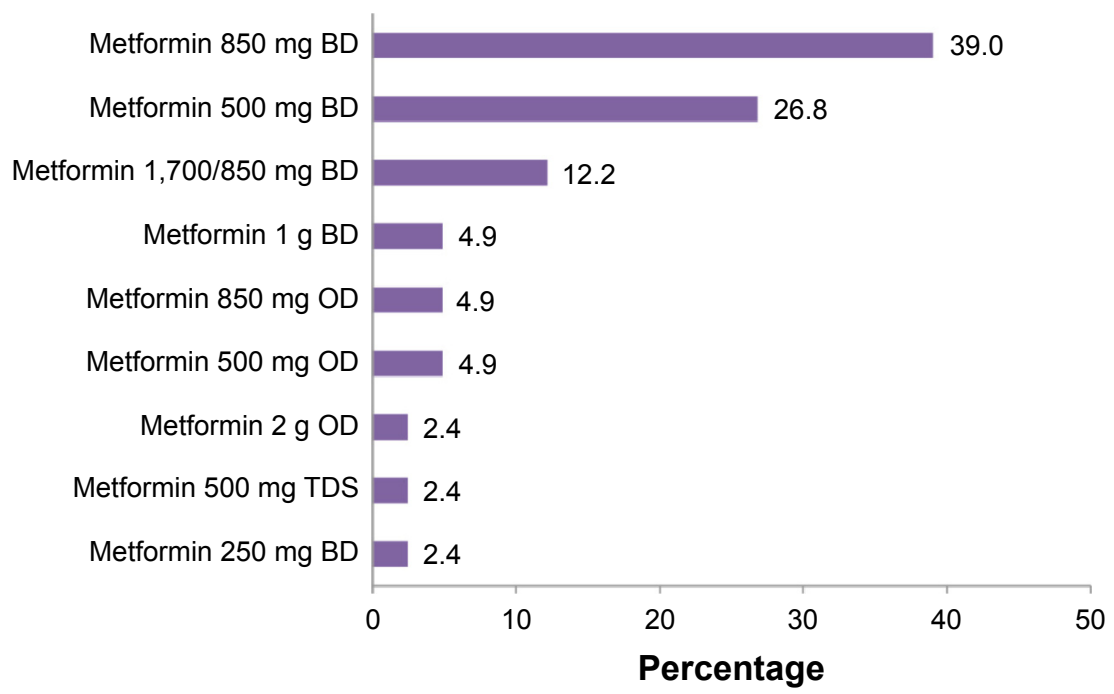

Figure 5 Dosage regimens of biguanides $(n=41)$.

Abbreviations: BD, twice daily; OD, once daily; TDS, thrice daily. 


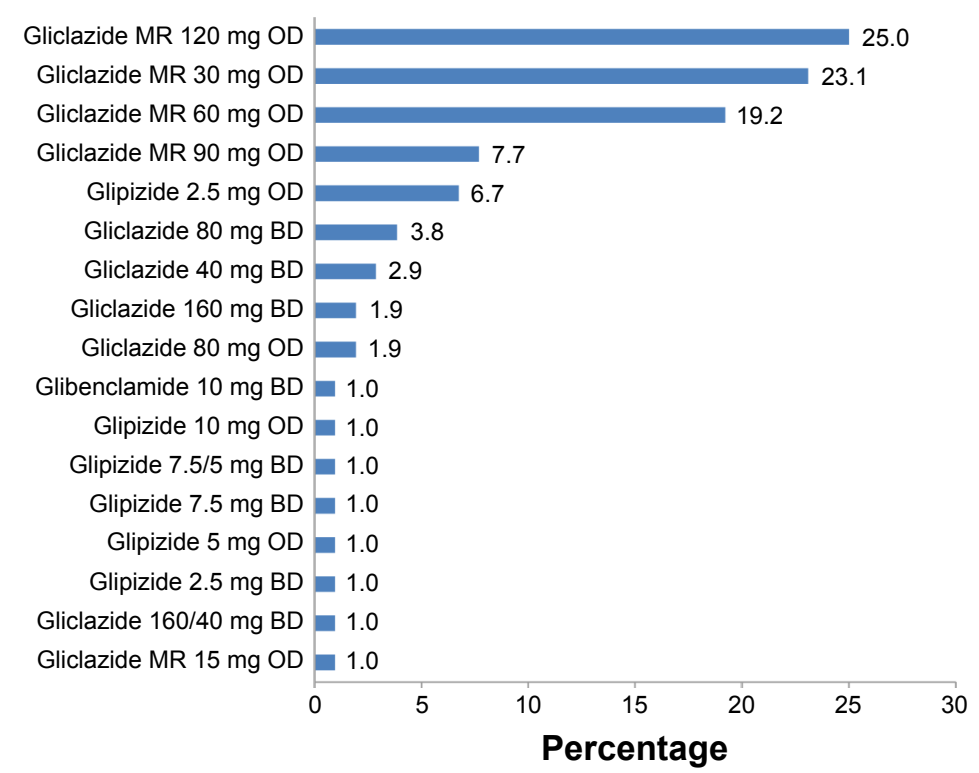

Figure 6 Dosage regimens of sulfonylureas $(n=104)$.

Abbreviations: $B D$, twice daily; MR, modified release; OD, once daily.

\section{Concurrent medications}

As illustrated in Figure 9, statins were the most frequently prescribed medications among all classes of concurrent drugs. Other concurrent medications included trimetazidine (number of patients, $n=13)$, ketosteril $(n=14)$, sodium bicarbonate $(n=14)$, potassium chloride $(n=9), H 2$ blockers $(n=7)$, thyroid replacement therapy $(n=6)$, centrally acting antihypertensives (moxonidine) $(n=4), \beta$-agonist inhalers $(n=5)$, antiarrhythmias $(n=4)$, glucosamine supplement $(n=4), 5$ - $\alpha$-reductase inhibitors $(n=4)$, Kalimate $(n=3)$, cholesterol absorption inhibitors $(n=3)$, antiepileptics $(n=3)$, selective serotonin receptor inhibitors $(n=3)$, antipsychotics $(n=2)$, antivirals $(n=1)$, antithyroid agents $(\mathrm{n}=1)$, phosphodiesterase type 5 (PDE5) inhibitors $(\mathrm{n}=1)$, and $N$-methyl-D-aspartate (NMDA) receptor antagonists $(\mathrm{n}=1)$.

\section{Association between antidiabetic regimens with glycemic control in T2DM patients with renal complications}

The use of different types of antidiabetic regimens, consisting of either a single class or a combination of different classes of antidiabetic drugs, was identified in the study population and is shown in Table 5.

Table 6 reports the association of antidiabetic regimens with glycemic control in T2DM patients with renal complications. Use of SUs alone $\left(\chi^{2}=17.968, d f=1, P<0.001\right)$, insulin alone $\left(\chi^{2}=8.025, d f=1, P=0.005\right)$, or a combination of biguanides and insulin $\left(\chi^{2}=4.310, d f=1, P=0.038\right)$ was found to be significantly associated with glycemic control, whereas other antidiabetic regimens did not show any significant association $(P>0.05)$.

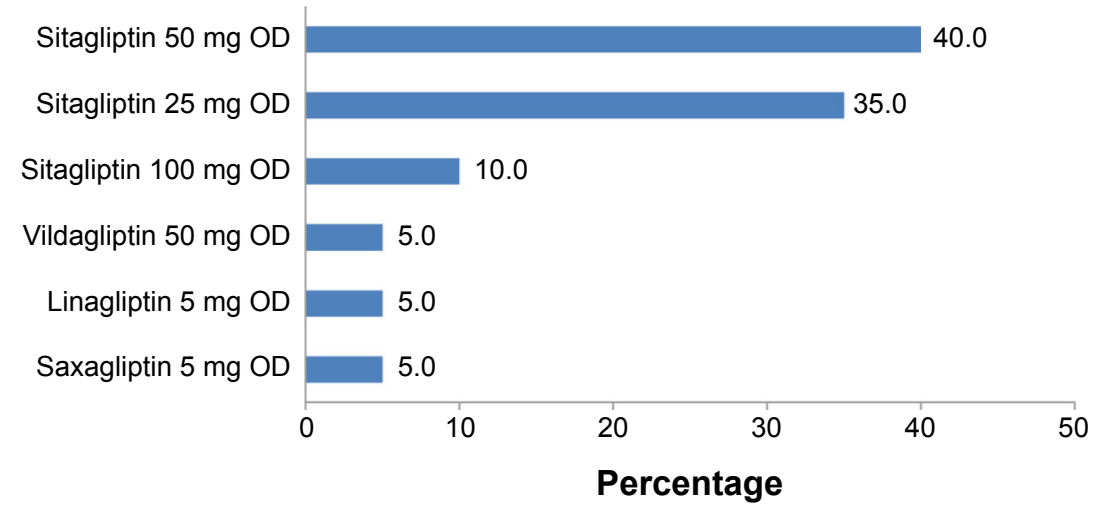

Figure 7 Dosage regimens of DPP-4 inhibitors $(n=20)$.

Abbreviations: OD, once daily; DPP-4, dipeptidyl peptidase-4. 


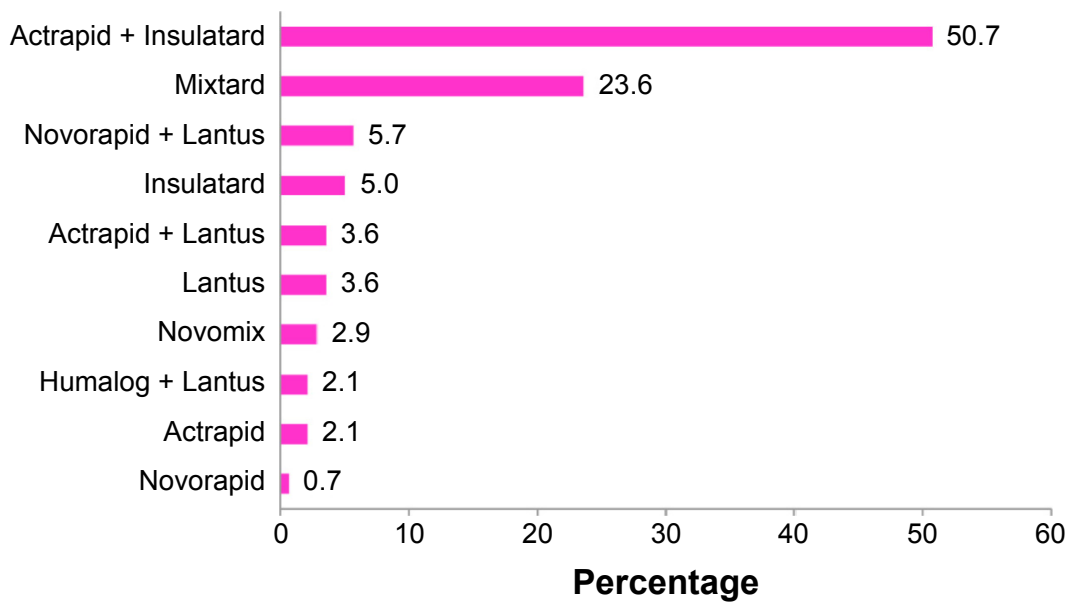

Figure 8 Insulin regimens used in patients $(n=\mid 40)$.

From the utilization pattern, it was observed that a higher proportion of patients $(68.3 \%$ ) receiving SUs showed good glycemic control. On the other hand, majority of the patients who were prescribed with insulin therapy or combination of biguanides and insulin showed poor glycemic control, with percentage of $65.5 \%$ and $85.7 \%$, respectively.

\section{Factors associated with glycemic control in T2DM patients with renal complications \\ Demographic and clinical characteristics}

Among the patients' demographic and clinical characteristics, only duration of T2DM $\left(\chi^{2}=13.067, d f=3, P=0.004\right)$ showed a significant association with glycemic control. Most of the patients with T2DM duration of more than 10 years tended to show poor glycemic control, whereas those with duration of 10 years and below were more likely to have a better glucose profile. Association between demographic and clinical characteristics with glycemic control in T2DM patients with renal complications is shown in Table 7.

\section{Comorbidities}

In terms of comorbidities, anemia $\left(\chi^{2}=5.124, d f=1\right.$, $P=0.024)$ and retinopathy $\left(\chi^{2}=4.533, d f=1, P=0.033\right)$ were proposed to have a significant association with $\mathrm{A} 1 \mathrm{C}$ levels (Table 8).

\section{Concurrent medications}

A total of three concurrent medications were found to have a significant association with glycemic control, including

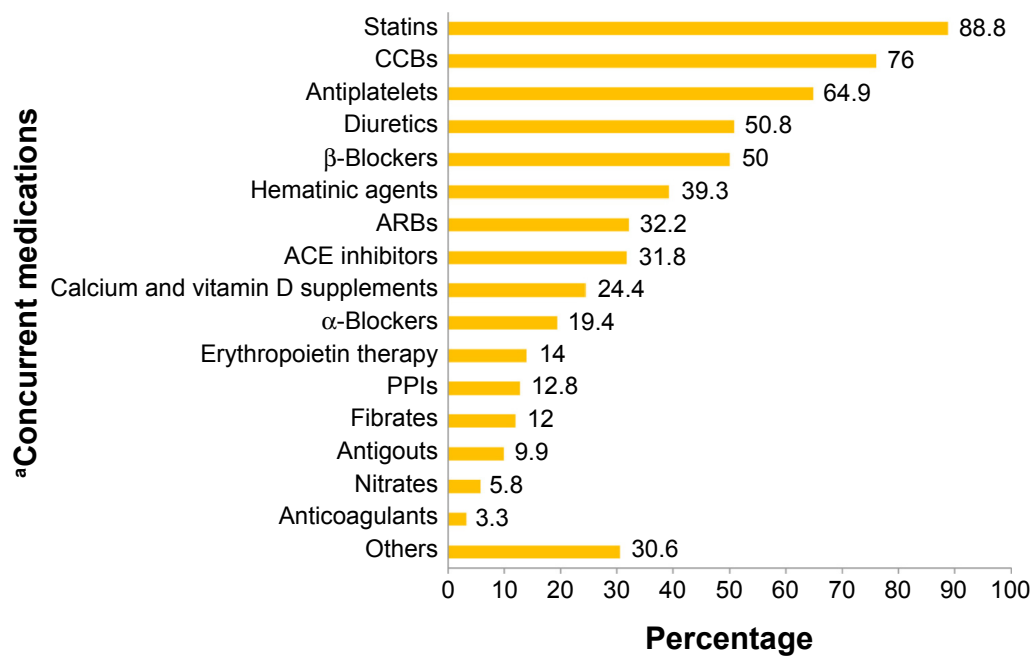

Figure 9 Concurrent medications of T2DM patients with renal complications ( $\mathrm{N}=242$ ).

Note: ${ }^{\mathrm{A} A}$ patient may receive more than one concurrent medication.

Abbreviations: ARBs, angiotensin II receptor blockers; CCBs, calcium channel blockers; ACE, angiotensin-converting enzyme; PPIs, proton pump inhibitors; T2DM, type 2 diabetes mellitus. 
Table 5 Antidiabetic regimens used in T2DM patients with renal complications $(\mathrm{N}=242)$

\begin{tabular}{ll}
\hline Antidiabetic regimens & Number of patients (\%) \\
\hline Single class & $183(75.6)$ \\
Biguanides & $4(1.7)$ \\
SUs & $63(26.0)$ \\
DPP4ls & $3(1.2)$ \\
Insulin & $113(46.7)$ \\
Combination of classes & $59(24.4)$ \\
Biguanides + SUs & $15(6.2)$ \\
Biguanides + Insulin & $14(5.8)$ \\
SUs + AGls & $3(1.2)$ \\
SUs + DPP4ls & $8(3.3)$ \\
SUs + insulin & $5(2.1)$ \\
DPP4ls + insulin & $4(1.7)$ \\
Biguanides + SUs + AGls & $1(0.4)$ \\
Biguanides + SUs + DPP4ls & $3(1.2)$ \\
Biguanides + SUs + insulin & $4(1.7)$ \\
SUs + AGls + DPP4ls & $2(0.8)$ \\
\hline
\end{tabular}

Abbreviations: AGls, $\alpha$-glucosidase inhibitors; DPP4ls, DPP-4 inhibitors; DPP-4, dipeptidyl peptidase-4; SUs, sulfonylureas; T2DM, type 2 diabetes mellitus.

hematopoietic growth factors $\left(\chi^{2}=3.929, d f=1, P=0.047\right)$, $\alpha$-blockers $\left(\chi^{2}=4.549, d f=1, P=0.033\right)$, and antigouts $\left(\chi^{2}=8.628, d f=1, P=0.003\right)$ (Table 9).

\section{Discussion}

\section{Medications used in T2DM patients with renal complications: antidiabetic medications}

\section{Biguanides}

Metformin acts by suppressing gluconeogenesis and thus causes reduction in hepatic glucose production and glucose levels. As the first-line antidiabetic agent in the management of T2DM, only $16.9 \%$ of patients were prescribed with metformin in this study. This can be explained by contraindication of biguanides in patients with moderate to advanced stages of CKD (eGFR $<30 \mathrm{~mL} / \mathrm{min} / 1.73 \mathrm{~m}^{2}$ ), according to the Clinical Practice Guidelines on Management of Type 2 Diabetes Mellitus, ${ }^{14}$ due to the possible risk of lactic acidosis. Among the study population, majority of patients on metformin were prescribed with a dose of either 850 or $500 \mathrm{mg}$ twice daily, which was the usual maintenance dose for adults with T2DM.

In this study, the use of biguanides in T2DM patients was found to be associated with stages of CKD. By observing the utilization pattern of biguanides, it was found that none of the ESRF patients in this study population was prescribed with metformin, but there were still $9.5 \%$ of patients with CKD stage 4 who received metformin. Although metformin is contraindicated in patients with eGFR less than
Table 6 Association between antidiabetic regimens and glycemic control in T2DM patients with renal complications

\begin{tabular}{|c|c|c|c|c|}
\hline \multirow[t]{2}{*}{ Antidiabetic regimens } & & \multicolumn{3}{|c|}{ Number of patients (\%) } \\
\hline & & $\begin{array}{l}A \mid C<7 \% \\
(n=108)\end{array}$ & $\begin{array}{l}A \mid C \geq 7 \% \\
(n=134)\end{array}$ & $P$-value \\
\hline \multicolumn{5}{|l|}{ Single class } \\
\hline \multirow[t]{2}{*}{ SUs } & Yes & $43(68.3)$ & $20(31.7)$ & $<0.00 \mathrm{I}^{\mathrm{a}, *}$ \\
\hline & No & $65(36.3)$ & $114(63.7)$ & \\
\hline \multirow[t]{2}{*}{ Insulin } & Yes & $39(34.5)$ & $74(65.5)$ & $0.005^{\mathrm{a}, *}$ \\
\hline & No & $69(53.5)$ & $60(46.5)$ & \\
\hline \multirow[t]{2}{*}{ Biguanides } & Yes & $3(75.0)$ & I (25.0) & $0.327^{b}$ \\
\hline & No & $105(44.1)$ & I33 (55.9) & \\
\hline \multirow[t]{2}{*}{ DPP4ls } & Yes & $2(66.7)$ & I (33.3) & $0.587^{b}$ \\
\hline & No & $106(44.4)$ & $133(55.6)$ & \\
\hline \multicolumn{5}{|l|}{ Combination of classes } \\
\hline \multirow[t]{2}{*}{ Biguanides + insulin } & Yes & $2(14.3)$ & $12(85.7)$ & $0.038^{\mathrm{a}, *}$ \\
\hline & No & $106(46.5)$ & $122(53.5)$ & \\
\hline \multirow[t]{2}{*}{ Biguanides + SUs } & Yes & $8(53.3)$ & $7(46.7)$ & $0.666^{\mathrm{a}}$ \\
\hline & No & $100(44.1)$ & $127(55.9)$ & \\
\hline \multirow[t]{2}{*}{$\mathrm{SUs}+\mathrm{AGls}$} & Yes & $0(0.0)$ & $3(100.0)$ & $0.256^{\mathrm{b}}$ \\
\hline & No & $108(45.2)$ & |3| (54.8) & \\
\hline \multirow[t]{2}{*}{ SUs + DPP4ls } & Yes & $5(62.5)$ & $3(37.5)$ & $0.472^{\mathrm{b}}$ \\
\hline & No & $103(44.0)$ & $|3|(56.0)$ & \\
\hline \multirow[t]{2}{*}{ SUs + insulin } & Yes & I $(20.0)$ & $4(80.0)$ & $0.384^{b}$ \\
\hline & No & $107(45.1)$ & $130(54.9)$ & \\
\hline \multirow[t]{2}{*}{ DPP4ls + insulin } & Yes & I $(25.0)$ & $3(75.0)$ & $0.63 I^{b}$ \\
\hline & No & $107(45.0)$ & $|3|(55.0)$ & \\
\hline \multirow[t]{2}{*}{ Biguanides + SUs + AGls } & Yes & $\mathrm{I}(100.0)$ & $0(0.0)$ & $0.446^{b}$ \\
\hline & No & $107(44.4)$ & $134(55.6)$ & \\
\hline \multirow[t]{2}{*}{ Biguanides + SUs + DPP4ls } & Yes & I (33.3) & $2(66.7)$ & $1.000^{\mathrm{b}}$ \\
\hline & No & $107(44.8)$ & $132(55.2)$ & \\
\hline \multirow[t]{2}{*}{ Biguanides + SUs + insulin } & Yes & I $(25.0)$ & $3(75.0)$ & $0.63 I^{b}$ \\
\hline & No & $107(45.0)$ & $|3|(55.0)$ & \\
\hline \multirow[t]{2}{*}{ SUs + AGls + DPP4ls } & Yes & I (50.0) & I $(50.0)$ & $1.000^{\mathrm{b}}$ \\
\hline & No & $107(44.6)$ & $133(55.4)$ & \\
\hline
\end{tabular}

Notes: " Computed using continuity correction; 'bomputed using Fisher's exact test; *statistically significant $(P<0.05)$.

Abbreviations: AGls, $\alpha$-glucosidase inhibitors; DPP4ls, DPP-4 inhibitors; DPP-4, dipeptidyl peptidase-4; SUs, sulfonylureas; T2DM, type 2 diabetes mellitus; AIC, glycated hemoglobin.

$30 \mathrm{~mL} / \mathrm{min} / 1.73 \mathrm{~m}^{2}$ as mentioned earlier, a recent study did agree with the use of metformin in CKD stage 4 patients with special conditions that patients should receive metformin with a maximum daily dose of $500 \mathrm{mg}$ besides having a stable eGFR. ${ }^{25}$ Because metformin was associated with lower risks of diabetic macrovascular complications, ${ }^{25}$ both benefits and risks of metformin should be considered in patients with moderate to advanced stages of CKD before any decision of continuing or discontinuing the drug is made in order to prevent complications as well as avoid adverse events induced by metformin.

\section{Sulfonylureas}

SUs are insulin secretagogues that act by promoting insulin secretion through binding to SUs receptors. SUs were widely used in more than $40 \%$ of the study population for the 
Table 7 Association between demographic and clinical characteristics with glycemic control in T2DM patients with renal complications

\begin{tabular}{|c|c|c|c|c|}
\hline \multirow[t]{2}{*}{ Concurrent medications } & \multirow[t]{2}{*}{$\mathbf{N}$} & \multicolumn{3}{|c|}{ Number of patients (\%) } \\
\hline & & AIC $<7 \%$ & $A \mid C \geq 7 \%$ & $P$-value \\
\hline Duration (years) & 223 & & & $0.004^{c, *}$ \\
\hline$\leq 10$ & & $40(59.7)$ & $27(40.3)$ & \\
\hline $10-20$ & & $35(42.7)$ & $47(57.3)$ & \\
\hline $20-30$ & & $16(31.4)$ & $35(68.6)$ & \\
\hline$\geq 30$ & & $6(26.1)$ & $17(73.9)$ & \\
\hline Sex & 242 & & & $0.764^{a}$ \\
\hline Male & & $51(43.2)$ & $67(56.8)$ & \\
\hline Female & & $57(46.0)$ & $67(54.0)$ & \\
\hline Age group & 242 & & & $0.465^{\mathrm{a}}$ \\
\hline Non-elderly & & $44(4 \mid .5)$ & $62(58.5)$ & \\
\hline Elderly & & $64(47.1)$ & $72(52.9)$ & \\
\hline Ethnicity & 242 & & & $0.106^{b}$ \\
\hline Malay & & $4 \mid(4 I .8)$ & $57(58.2)$ & \\
\hline Chinese & & $44(53.0)$ & $39(47.0)$ & \\
\hline Indian & & $22(36.7)$ & $38(63.3)$ & \\
\hline Others & & I (100.0) & $0(0.0)$ & \\
\hline BMI & 153 & & & $0.193^{b}$ \\
\hline Underweight & & I (50.0) & I (50.0) & \\
\hline Normal & & $14(60.9)$ & $9(39.1)$ & \\
\hline Pre-obese & & $24(39.3)$ & $37(60.7)$ & \\
\hline Obese & & $25(37.3)$ & $42(62.7)$ & \\
\hline Smoking & 186 & & & $0.304^{c}$ \\
\hline Yes & & $5(3 \mid .2)$ & II (68.8) & \\
\hline No & & $61(46.6)$ & $70(53.4)$ & \\
\hline Ex-smoker & & $14(35.9)$ & $25(64.1)$ & \\
\hline Family history of T2DM & 113 & & & $0.843^{\mathrm{a}}$ \\
\hline Yes & & $23(39.0)$ & $36(6 \mid .0)$ & \\
\hline No & & $23(42.6)$ & $31(57.4)$ & \\
\hline Albuminuria & 44 & & & $1.000^{\mathrm{b}}$ \\
\hline Normal to mildly increased & & $0(0.0)$ & $2(100.0)$ & \\
\hline Moderately increased & & $3(37.5)$ & $5(62.5)$ & \\
\hline Severely increased & & II (32.4) & $23(67.6)$ & \\
\hline Proteinuria & 113 & & & $0.129^{b}$ \\
\hline Normal to mildly increased & & $3(60.0)$ & $2(40.0)$ & \\
\hline Moderately increased & & $17(65.4)$ & $9(34.6)$ & \\
\hline Severely increased & & $35(42.7)$ & $47(57.3)$ & \\
\hline Polypharmacy & 242 & & & $0.852^{\mathrm{a}}$ \\
\hline Yes & & $100(44.2)$ & $126(55.8)$ & \\
\hline No & & $8(50.0)$ & $8(50.0)$ & \\
\hline
\end{tabular}

Notes: ${ }^{2}$ Computed using continuity correction; ${ }^{b}$ computed using Fisher's exact test; computed using Pearson chi-square test; *statistically significant $(P<0.05)$.

Abbreviations: BMI, body mass index; T2DM, type 2 diabetes mellitus AIC, glycated hemoglobin.

management of T2DM. Gliclazide MR was the most commonly prescribed agent among SUs antidiabetic drugs in this study, followed by gliclazide, glipizide, and glibenclamide. A randomized controlled trial that compared gliclazide MR and gliclazide had found that the former can better improve blood glucose control in addition to enhance patient's compliance due to its once-daily dosing. ${ }^{26}$ Intensive glycemic control using gliclazide MR was also proven to be able to reduce development of ESRF as well as improve albuminuria
Table 8 Association between comorbidities and glycemic control in T2DM patients with renal complications

\begin{tabular}{|c|c|c|c|c|}
\hline \multirow[t]{2}{*}{ Comorbidities } & & \multicolumn{3}{|c|}{ Number of patients (\%) } \\
\hline & & $\begin{array}{l}A \mid C<7 \% \\
(n=108)\end{array}$ & $\begin{array}{l}A \mid C \geq 7 \% \\
(n=\mid 34)\end{array}$ & $P$-value \\
\hline \multirow[t]{2}{*}{ Anemia $(n=2 \mid 6)$} & Yes & $81(5 \mid .3)$ & 77 (48.7) & $0.024^{a, *}$ \\
\hline & No & $19(32.8)$ & $39(67.2)$ & \\
\hline \multirow[t]{2}{*}{ Retinopathy } & Yes & $30(34.9)$ & $56(65 . I)$ & $0.033^{\mathrm{a}, *}$ \\
\hline & No & $78(50.0)$ & $78(50.0)$ & \\
\hline \multirow[t]{2}{*}{ Hypertension } & Yes & $107(44.8)$ & $132(55.2)$ & $1.000^{\mathrm{b}}$ \\
\hline & No & I (33.3) & $2(66.7)$ & \\
\hline \multirow[t]{2}{*}{ Dyslipidemia } & Yes & $58(39.7)$ & $88(60.3)$ & $0.078^{\mathrm{a}}$ \\
\hline & No & $50(52.1)$ & $46(47.9)$ & \\
\hline \multirow[t]{2}{*}{ Fatty liver disease } & Yes & $4(57.1)$ & $3(42.9)$ & $0.547^{\mathrm{b}}$ \\
\hline & No & $104(44.3)$ & $|3|(55.7)$ & \\
\hline \multirow[t]{2}{*}{ Obesity $(n=153)$} & Yes & $25(37.3)$ & $42(62.7)$ & $0.404^{\mathrm{a}}$ \\
\hline & No & $39(45.3)$ & $47(54.7)$ & \\
\hline \multirow[t]{2}{*}{ Ischemic heart disease } & Yes & $33(42.3)$ & $45(57.7)$ & $0.717^{\mathrm{a}}$ \\
\hline & No & 75 (45.7) & $89(54.3)$ & \\
\hline \multirow[t]{2}{*}{ Stroke } & Yes & $14(40.0)$ & $21(60.0)$ & $0.68 I^{\mathrm{a}}$ \\
\hline & No & $94(45.4)$ & II $3(54.6)$ & \\
\hline \multirow[t]{2}{*}{ Heart failure } & Yes & $6(40.0)$ & $9(60.0)$ & $0.917^{\mathrm{a}}$ \\
\hline & No & $102(44.9)$ & $125(55.1)$ & \\
\hline \multirow[t]{2}{*}{ Gout } & Yes & $12(66.7)$ & $6(33.3)$ & $0.088^{\mathrm{a}}$ \\
\hline & No & $96(42.9)$ & $128(57.1)$ & \\
\hline Benign prostate & Yes & $10(58.8)$ & $7(4 \mid .2)$ & $0.333^{\mathrm{a}}$ \\
\hline hyperplasia & No & $98(43.6)$ & $127(56.4)$ & \\
\hline \multirow[t]{2}{*}{ Neuropathy } & Yes & $2(25.0)$ & $6(75.0)$ & $0.304^{b}$ \\
\hline & No & $106(45.3)$ & $128(54.7)$ & \\
\hline \multirow[t]{2}{*}{ Cancer } & Yes & $5(83.3)$ & I (I6.7) & $0.092^{\mathrm{b}}$ \\
\hline & No & $103(43.6)$ & $133(56.4)$ & \\
\hline \multirow[t]{2}{*}{ Others } & Yes & $20(55.6)$ & $16(44.4)$ & $0.549^{\mathrm{a}}$ \\
\hline & No & $88(42.7)$ & I I 8 (57.3) & \\
\hline
\end{tabular}

Notes: a Computed using continuity correction; ' ${ }^{\mathrm{b}}$ computed using Fisher's exact test; *statistically significant $(P<0.05)$.

Abbreviation: T2DM, type 2 diabetes mellitus; AIC, glycated hemoglobin.

in diabetes patients. ${ }^{27}$ Moreover, gliclazide is safe for use in patients with renal failure. ${ }^{19,28}$ Thus, the advantages of gliclazide greatly increased its popularity among T2DM patients with CKD.

In this study, the most common dosage regimen prescribed among the study population was gliclazide MR $120 \mathrm{mg}$ once daily, which was also the maximum recommended dose for this drug. Comparably, another study also reported that more than $70 \%$ of patients on gliclazide MR received a dose of $120 \mathrm{mg}$ daily. ${ }^{29}$ Besides gliclazide, glipizide is also a preferred antidiabetic agent in CKD patients without the need for dose adjustment, whereby it was used with a dose ranging from 2.5 to $15 \mathrm{mg}$ daily in this study. Therefore, we can see that both gliclazide and glipizide were widely used among patients with CKD for the sake of a better glycemic profile in long-term T2DM management without any dose reduction required. 
Table 9 Association between concurrent medications and glycemic control in T2DM patients with renal complications

\begin{tabular}{|c|c|c|c|c|}
\hline \multirow{2}{*}{$\begin{array}{l}\text { Concurrent } \\
\text { medications }\end{array}$} & & \multicolumn{3}{|c|}{ Number of patients (\%) } \\
\hline & & \multirow{2}{*}{$\begin{array}{l}A \mid C<7 \% \\
(n=108) \\
21(61.8)\end{array}$} & \multirow{2}{*}{$\begin{array}{l}A \mid C \geq 7 \% \\
(n=134)\end{array}$} & $P$-value \\
\hline Hematopoietic growth & Yes & & & $0.047^{a, *}$ \\
\hline factors & No & $87(41.8)$ & $12 \mid(58.2)$ & \\
\hline \multirow[t]{2}{*}{$\alpha$-Blockers } & Yes & $28(59.6)$ & $19(40.4)$ & $0.033^{\mathrm{a}, *}$ \\
\hline & No & $80(4 \mid .0)$ & $115(59.0)$ & \\
\hline \multirow[t]{2}{*}{ Antigouts } & Yes & $18(75.0)$ & $6(25.0)$ & $0.003^{\mathrm{a}, *}$ \\
\hline & No & $90(4 \mid .3)$ & $128(58.7)$ & \\
\hline \multirow[t]{2}{*}{ ACE inhibitors } & Yes & $28(36.4)$ & $49(63.6)$ & $0.104^{\mathrm{a}}$ \\
\hline & No & $80(48.5)$ & $85(5 \mid .5)$ & \\
\hline Angiotensin II receptor & Yes & $33(42.3)$ & $45(57.7)$ & $0.717^{a}$ \\
\hline blockers & No & $75(45.7)$ & $89(54.3)$ & \\
\hline Calcium channel & Yes & $84(45.7)$ & $100(54.3)$ & $0.675^{\mathrm{a}}$ \\
\hline blockers & No & $24(4 \mid .4)$ & $34(58.6)$ & \\
\hline \multirow[t]{2}{*}{$\beta$-Blockers } & Yes & $48(39.7)$ & $73(60.3)$ & $0.155^{\mathrm{a}}$ \\
\hline & No & $60(49.6)$ & $6 \mathrm{I}(50.4)$ & \\
\hline \multirow[t]{2}{*}{ Diuretics } & Yes & $53(43.1)$ & $70(56.9)$ & $0.719^{\mathrm{a}}$ \\
\hline & No & $55(46.2)$ & $64(53.8)$ & \\
\hline \multirow[t]{2}{*}{ Antiplatelets } & Yes & $73(46.5)$ & $84(53.5)$ & $0.510^{\mathrm{a}}$ \\
\hline & No & $35(4 \mid .2)$ & $50(58.8)$ & \\
\hline \multirow[t]{2}{*}{ Anticoagulants } & Yes & $2(25.0)$ & $6(75.0)$ & $0.304^{b}$ \\
\hline & No & $106(45.3)$ & $128(54.7)$ & \\
\hline \multirow[t]{2}{*}{ Nitrates } & Yes & $6(42.9)$ & $8(57.1)$ & $1.000^{\mathrm{a}}$ \\
\hline & No & $102(44.7)$ & $126(55.3)$ & \\
\hline \multirow[t]{2}{*}{ Statins } & Yes & $93(43.3)$ & $122(56.7)$ & $0.314^{\mathrm{a}}$ \\
\hline & No & $15(55.6)$ & $12(44.4)$ & \\
\hline \multirow[t]{2}{*}{ Fibrates } & Yes & $14(48.3)$ & $15(51.7)$ & $0.874^{\mathrm{a}}$ \\
\hline & No & $94(44.1)$ & $119(55.9)$ & \\
\hline \multirow[t]{2}{*}{ Hematinic agents } & Yes & $48(50.5)$ & $47(49.5)$ & $0.177^{\mathrm{a}}$ \\
\hline & No & $60(40.8)$ & 87 (59.2) & \\
\hline Calcium and vitamin D & Yes & $32(54.2)$ & $27(45.8)$ & $0.120^{\mathrm{a}}$ \\
\hline supplements & No & $76(4 \mid .5)$ & $107(58.5)$ & \\
\hline Proton pump & Yes & $19(6 \mid .3)$ & $12(38.7)$ & $0.07 I^{\mathrm{a}}$ \\
\hline inhibitors & No & $89(42.2)$ & $122(57.8)$ & \\
\hline \multirow[t]{2}{*}{ Others } & Yes & $38(51.4)$ & $36(48.6)$ & $0.209^{\mathrm{a}}$ \\
\hline & No & $70(4 \mid .7)$ & $98(58.3)$ & \\
\hline
\end{tabular}

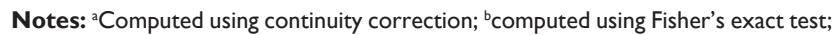
*statistically significant $(P<0.05)$.

Abbreviations: T2DM, type 2 diabetes mellitus; AIC, glycated hemoglobin; ACE, angiotensin-converting enzyme.

\section{$\alpha$-Glucosidase inhibitors}

$\alpha$-Glucosidase inhibitors slow the breakdown of carbohydrates in the small intestine through inhibiting $\alpha$-glucosidase enzymes, thus decreasing the glucose absorption and postprandial hyperglycemia. Acarbose was known as the least prescribed antidiabetic agent in this study, which involved merely six patients among the study population. It was used as an add-on therapy instead of monotherapy with the possible reason that it had lower efficacy of glycemic control in diabetes patients. ${ }^{30}$ Number of patients who received acarbose $100 \mathrm{mg}$ thrice daily and acarbose $50 \mathrm{mg}$ thrice daily was only differed by one patient in this study. A systematic review demonstrated that acarbose with a dose of $50 \mathrm{mg}$ thrice daily was sufficient, because higher dose conferred no extra benefit on glucose lowering, but induced more side effects of the drug. ${ }^{31}$ Although it was shown that acarbose can reduce cardiovascular complications in T2DM patients, ${ }^{32}$ yet, due to failure of several studies to prove its superiority over other oral antidiabetic agents, ${ }^{33-35}$ acarbose should be indicated only in patients who are unable to use other oral drugs. Also, gastrointestinal side effects of acarbose such as flatulence and diarrhea as well as lack of evidence of using acarbose in patients with renal insufficiency made it less favorable. ${ }^{30}$ Thus, this explained the limited use of acarbose which had been shown in this study.

\section{DPP-4 inhibitors}

DPP-4 inhibitors, also referred to as incretin enhancers, are antidiabetic drugs that inhibit enzyme that degrades GLP-1, thereby prolong the action of GLP-1 in insulin secretion. Similar to acarbose, no monotherapy-involved DPP-4 inhibitors were observed in the study population whereby they were prescribed in combination with other antidiabetic agents. Despite comparable efficacy and side-effect profiles, ${ }^{36}$ sitagliptin emerged as the drug of choice in patients who received DPP-4 inhibitors in this study. It was most probable, because sitagliptin was the first DPP-4 inhibitor being approved for diabetes treatment ${ }^{36}$ in addition to its ability to provide optimal blood glucose control in diabetic CKD patients including those with ESRF on dialysis. ${ }^{37}$ It is also important to note that in patients with moderate to severe $\mathrm{CKD}$, sitagliptin requires dose reduction of $50 \%-75 \% .{ }^{38}$ Therefore, sitagliptin with either 25 or $50 \mathrm{mg}$ once-daily doses was more frequently prescribed in this patient population compared with its usual maintenance dose which was $100 \mathrm{mg}$ once daily.

\section{Insulin}

More than a half of diabetic patients with CKD in this study were prescribed with insulin for their glycemic control. In this study population, combination of short-acting insulin Actrapid and long-acting insulin Insulatard turned out to be the most commonly used insulin regimen. The benefits of using multiple insulin injections which constitute of short-acting insulin at each meals and long-acting insulin at bedtime over conventional insulin therapy with once or twice daily injections of intermediate-acting insulin were proven in studies by Ohkubo et al ${ }^{39}$ and Shichiri et al. ${ }^{10}$ Both of the studies found that multiple insulin injections had successfully prevented and delayed the progression of microvascular complications of diabetes, whereby this positive outcome served as the main objective for glycemic control in T2DM 
patients with renal complications. Besides that, due to the flexibility for doses adjustment based on premeal and pre-bed blood glucose levels, combination of Actrapid and Insulatard seemed to be more favorable than intermediate-acting insulin such as Mixtard in this case. On the other hand, other insulin agents such as NovoRapid, Lantus, and NovoMix were seldom used as they are under the special formulary in the UMMC which are only allowed to be prescribed by endocrinologists.

\section{Medications used in T2DM patients with renal complications: concurrent medications}

Among several classes of concurrent medications, statins appeared to be the most frequently used medications. Due to the high risk of developing cardiovascular complications in diabetes patients with $\mathrm{CKD}$, it was recommended that all the patients aged above 40 years old which were found in approximately $98 \%$ among this patient population, as well as those with overt cardiovascular disease should be treated with a statin, regardless of baseline low density lipoprotein cholesterol levels. ${ }^{14}$ Hence, statins were not only used for treatment of dyslipidemia, but also used as primary prophylaxis of cardiovascular disease in this study population.

Similar to another study conducted in the UMMC, ${ }^{40} \mathrm{cal}-$ cium channel blockers were the most commonly prescribed drug class among antihypertensive agents, indicating the prescribing pattern that had been practiced in this setting although ACE inhibitors served as first-line treatment for diabetic patients with CKD. ${ }^{7}$ Also, antiplatelets were widely used among the study population, primarily aspirin. The American Diabetes Association ${ }^{7}$ suggested that antiplatelet agents should be considered as primary prevention in patients with increasing risk of cardiovascular disease, especially male patients aged above 50 years old and female patients aged above 60 years old with at least one major risk factor, such as hypertension, which was found in most of the patients. Therefore, from the utilization of concurrent medications in this study, we can see that besides good glycemic control, additional drug therapy is needed for diabetes patients to prevent occurrence of macrovascular complications that may be threatening to patients.

\section{Association between antidiabetic regimens with glycemic control in T2DM patients with renal complications}

There were arguments regarding the inaccuracy of A1C as the main parameter in evaluating glycemic status in patients with advanced stages of kidney disease. It is because in chronic renal failure patients, lifespan of erythrocytes is shortened and this causes reduction in exposure of erythrocytes to glycemia, thereby leading to falsely low A1C values. ${ }^{41}$ Glycated albumin had been proposed as a better indicator of glycemic index. Yet, due to its unavailability and limited data to prove its superiority over $\mathrm{A} 1 \mathrm{C}, \mathrm{A} 1 \mathrm{C}$ remains as the cornerstone for long-term glycemic monitoring in T2DM and CKD patients. ${ }^{42}$ Therefore, in this case, $\mathrm{A} 1 \mathrm{C}$ was being used as the main glycemic parameter in all the patients, regardless of stages of CKD.

Regarding antidiabetic regimens, use of SUs as monotherapy was found to be significantly associated with good glycemic control in T2DM patients with renal complications. A systematic review pertaining to effects of SUs on glycemic control had demonstrated that SUs was able to reduce A1C by approximately $1.5 \%$ when compared with placebo when used as monotherapy. ${ }^{43}$ This association was also supported by a local study, which reported that there were more T2DM patients who received SUs monotherapy had achieved A1C target of less than $6.5 \%$ when compared with metformin and other antidiabetic drugs. ${ }^{44}$ However, failure of diabetic patients to maintain good glycemic control in long-term use of SUs monotherapy was discovered by Cook et al. ${ }^{45}$ The contradicting findings were mainly due to the difference in time horizon and study design applied between our studies. Therefore, further studies should be done to investigate the association between the uses of SUs monotherapy and its long-term glycemic control in specifically T2DM patients with renal complications, because some of the antidiabetic drugs in the SUs group are generally well recommended for diabetic management in this patient population.

Consistent with other studies, patients on insulin therapy alone were significantly associated with poor glycemic control in this study. ${ }^{46-48}$ Unlike type $1 \mathrm{DM}$ in which insulin is the mainstay of treatment, use of insulin therapy in T2DM patients reflects either a deterioration in kidney functions which limits the choice of antidiabetic drug, or deterioration of diabetes over time which requires more aggressive treatment. ${ }^{49}$ Patients with the latter condition usually have their A1C levels arisen even when insulin are prescribed in appropriate doses due to decline in $\beta$-cells function or increase in insulin resistance over years..$^{50}$ This in turn indicates poor glycemic control in those patients, which explains the association between insulin therapy and glycemic control as found in this study.

Pertaining to combination of antidiabetic classes, a combination of biguanides and insulin was noticed to have a significant correlation with poor glycemic control. Previous 
studies had proven the association between combination of oral agents and insulin with glycemic control; ${ }^{46,47,49}$ however, these studies did not specifically mention the classes of oral agents involved in the association. Unsatisfactory glycemic control incurred by combination of insulin and oral drugs indicates that the use of different dosage forms of antidiabetic drugs might enhance difficulty for diabetic patients in administrating the medications, which in turn affects patients' compliance as well as glycemic control.

\section{Factors associated with glycemic control in T2DM patients with renal complications \\ Demographic and clinical characteristics}

Compared with other studies, duration of T2DM was found to be significantly associated with glycemic control in this study population. ${ }^{44,47-49}$ Ahmad et $\mathrm{al}^{44}$ reported that every additional year of duration of diabetes had reduced the possibility of achieving glycemic goals by $5 \%$. Longer duration of diabetes may imply the presence of progressive defects in insulin secretion due to $\beta$-cells failure, and this will unavoidably end up causing suboptimal patients' response to antidiabetic agents. ${ }^{49}$ Therefore, most of the time, patients who have long duration of diabetes tend to receive more complex antidiabetic regimens or higher doses of antidiabetic drugs in order to achieve better glycemic control.

\section{Comorbidities}

Anemia and diabetic retinopathy were the only two comorbidities that appeared to be associated with glycemic control. In this study, slightly more anemic patients were found to have $\mathrm{A} 1 \mathrm{C}$ of less than $7 \%$. Nevertheless, this finding was contradicted with Adejumo et $\mathrm{al}^{51}$ who concluded that incidence of anemia was associated with poor glycemic control in renally impaired diabetic patients. According to the NKF, ${ }^{19}$ falsely high A1C levels can be due to reduced erythrocytes lifespan or iron deficiency, whereas falsely low A1C can be caused by carbamylation of hemoglobin in CKD patients. Therefore, from the explanation, it was understood that both the scenarios were actually possible in patients with renal insufficiency.

It was not surprising that significant association was found between the presence of diabetic retinopathy with poor glycemic control in this study. This was in line with Sanal et $\mathrm{al}^{52}$ and Longo-Mbenza et $\mathrm{al}^{53}$ who also found the similar finding. Several mechanisms on the development of retinopathy caused by poor glycemic control had been postulated. One of the mechanisms is the increased flux of glucose through polyol pathway, resulting in accumulation of sorbitol which causes osmotic stress to vascular cells. In addition, oxidative stress brought by production of free radicals and reactive oxygen species as well as formation of advanced glycosylated end products induced by high glucose levels were also associated with microaneurysm formation in diabetic retinopathy. ${ }^{3}$

As proven by UKPDS Group ${ }^{9}$ and Patel et $\mathrm{al}^{12}$ in ADVANCE study, good glycemic control can prevent development and worsening of microvascular and macrovascular complications of DM. Although retinopathy was not as common as other diabetic complications as proven in several local studies, ${ }^{1,54,55}$ poor glycemic control can lead to retinopathy and this undeniably will affect patients' quality of life. In short, patients should be aware of the importance of good glycemic control in order to prevent diabetes-related mortality and morbidity.

\section{Concurrent medications}

Among different classes of concurrent medications, hematopoietic growth factors, $\alpha$-blockers, and antigouts were reported to be significantly associated with glycemic control in this study.

Erythropoietin therapy, also known as hematopoietic growth factor, is commonly used in the control of anemia in CKD patients. In accordance with other studies, erythropoietin therapy led to significantly lower A1C levels in diabetes patients with CKD. ${ }^{56,57}$ Reduction in A1C levels was proposed to be secondary to the formation of new red blood cells stimulated by erythropoietin therapy, resulting in alteration of the proportion of new to old erythrocytes, or it can be caused by decreased glycation rate due to less exposure of new red blood cells to ambient glycemia. ${ }^{42,57}$ Therefore, interpretation of glycemic status by using A1C readings should be done with caution in diabetes patients who received hematopoietic growth factors.

$\alpha$-Blockers, which were indicated for hypertension and benign prostate hyperplasia, appeared to have a significant association with good glycemic control in this study. However, none of the specific agents in this group (prazosin, doxazosin, and alfuzosin) was found to be significantly correlated with A1C levels. Regarding this finding, Jasik et al ${ }^{58}$ had concluded that prazosin did not confer any effect on pancreatic $\beta$-cells, suggesting that there was no influence on rate of secretion of insulin by prazosin. Still, lack of recent studies demonstrating on the association of $\alpha$-blockers with glycemic control causes the underlying mechanism remains unclear. 
Similarly, antigouts were found to be significantly associated with good glycemic control in this study. This finding was comparable with Dogan et $\mathrm{a}^{59}$ and Mácsai, ${ }^{60}$ who reported that allopurinol therapy had led to significant reduction in A1C levels. Previous study found that hyperuricemia was correlated with increase in insulin resistance; thus it had been postulated that allopurinol acts by lowering serum uric acid levels and reducing oxidative stress to cause decrease in A1C level..$^{59}$ In short, because several concurrent medications were found to have association with glycemic control, more studies are required to be conducted in this direction in order to help in optimizing glycemic control in diabetic patients with renal complications.

\section{Limitations of the study}

This study possesses several limitations. First, retrospective nature of the study design caused the whole data collection process solely based on information available from patients' medical records. Dependence on medical records tends to incur bias and inaccurate results, especially in circumstances where there are missing data on patients' information which is relevant to the study. Important information might also be neglected or deliberately omitted due to illegible handwriting. Patients' adherence to antidiabetic medications also could not be assessed, unless adherence status is recorded in the case notes. Besides, cross-sectional study design made the causal relationship between variables cannot be studied.

In addition, convenient sampling applied in this study can somehow lead to selection bias. Also, sampling of subjects in merely one setting, UMMC, as well as small sample size implies that the demographic and clinical characteristics of this study population might not able to reflect or represent the actual scenarios of Malaysian populations. Therefore, the findings obtained from this study can only serve as preliminary data, whereby large-scale prospective studies involving several settings in different states of Malaysia are required to be carried out to prove the findings.

\section{Conclusion}

Antidiabetic regimens such as monotherapy SUs, insulin therapy, and combination of biguanides with insulin were found to have a significant association with glycemic control. On the other hand, other factors that correlated with glycemic control included duration of T2DM, comorbidities such as anemia and retinopathy as well as concurrent medications such as erythropoietin therapy, $\alpha$-blockers, and antigouts.

In conclusion, by identifying the common antidiabetic regimens used as well as factors associated with glycemic control, optimization of glucose control can be achieved in diabetic management of T2DM patients with renal complications, which in turn may help in retarding the progression of kidney disease and preventing onset of other diabetic-related complications.

\section{Acknowledgments}

The authors would like to thank the Ministry of Science, Technology and Innovation, Malaysia (Science fund: 12-0203-2097), and University of Malaya, Malaysia (RP024A-14HTM), for financial and technical support.

\section{Disclosure}

The authors report no conflicts of interest in this work.

\section{References}

1. Wan Nazaimoon WM, Md Isa SH, Wan Mohamad WB, et al. Prevalence of diabetes in Malaysia and usefulness of $\mathrm{HbA1c}$ as a diagnostic criterion. Diabet Med. 2013;30(7):825-828.

2. American Diabetes Association. Diagnosis and classification of diabetes mellitus. Diabetes Care. 2014a;37(1):S81-S90.

3. Fowler MJ. Microvascular and macrovascular complications of diabetes. Clin Diabetes. 2008;26(2):77-82.

4. Abougalambou SSI, Hassali MA, Sulaiman SAS, Abougalambou AS Prevalence of vascular complications among type 2 diabetes mellitus outpatients at teaching hospital in Malaysia. J Diabetes Metab. 2011; 2(115): $1-4$

5. National Kidney Foundation. K/DOQI clinical practice guidelines for chronic kidney disease: evaluation, classification, and stratification. $\mathrm{Am}$ J Kidney Dis. 2002;39(2):S1-S266.

6. American Diabetes Association. Nephropathy in diabetes. Diabetes Care 2004;27(1):S79-S83.

7. American Diabetes Association. Standards of medical care in diabetes2014. Diabetes Care. 2014b;37(1):S14-S80.

8. Lim YN, Lim TO. 15th Report of the Malaysian Dialysis and Transplant Registry 2007. Kuala Lumpur, Malaysia: National Renal Registry; 2008.

9. United Kingdom Prospective Diabetes Study (UKPDS) Group. Intensive blood glucose control with sulphonylureas or insulin compared with conventional treatment and risk of complications in patients with type 2 diabetes (UKPDS 33). The Lancet. 1998;352:837-853.

10. Shichiri M, Kishikawa H, Ohkubo Y, Wake N. Long-term results of the Kumamoto Study on optimal diabetes control in type 2 diabetic patients. Diabetes Care. 2000;23(2):B21-B29.

11. Duckworth W, Abraira C, Moritz T, et al. Glucose control and vascular complications in veterans with type 2 diabetes. $N$ Engl J Med. 2009, 360(2):129-139.

12. Patel A, MacMahon S, Chalmers J, et al. Intensive blood glucose control and vascular outcomes in patients with type 2 diabetes. NEngl JMed.2008, 358(24):2560-2572.

13. Garg R, Williams ME. Diabetes management in the kidney patient. Med Clin North Am. 2013;97(1):135-156.

14. Ministry of Health Malaysia. Clinical Practice Guidelines on Management of Type 2 Diabetes Mellitus. 4th ed. Putrajaya: Ministry of Health Malaysia; 2009

15. Kidney Disease: Improving Global Outcomes (KDIGO) CKD Work Group. KDIGO 2012 Clinical practice guideline for the evaluation and management of chronic kidney disease. Kidney Int. 2013;3:1-150.

16. Kirkman MS, Briscoe VJ, Clark N, et al. Diabetes in older adults Diabetes Care. 2012;35(12):2650-2664.

17. Ministry of Health Malaysia. Clinical Practice Guidelines on Management of Obesity. Putrajaya: Ministry of Health Malaysia; 2004. 
18. Ministry of Health Malaysia. Clinical Practice Guidelines on Management of Chronic Kidney Disease in Adults. Putrajaya: Ministry of Health Malaysia; 2011.

19. National Kidney Foundation. KDOQI clinical practice guidelines and clinical practice recommendations for diabetes and chronic kidney disease. Am J Kidney Dis. 2007;49(2):S1-S180.

20. Nobili A, Licata G, Salerno F, et al. Polypharmacy, length of hospital stay, and in-hospital mortality among elderly patients in internal medicine wards. The REPOSI study. Eur J Clin Pharmacol. 2011;67(5): 507-519.

21. Mosby, Inc. Mosby's Medical Dictionary. 8th ed. St Louis: Mosby; 2009.

22. Dorland's Illustrated Medical Dictionary. 32nd ed. Philadelphia: Saunders; 2012.

23. Boulton AJ, Vinik AI, Arezzo JC, et al. Diabetic neuropathies a statement by the American Diabetes Association. Diabetes Care. 2005; 28(4):956-962.

24. National Kidney Foundation. KDOQI clinical practice guidelines and clinical practice recommendations for anemia in chronic kidney disease in adults. Am J Kidney Dis. 2006;47(5):S16-S85.

25. Arnouts $P$, Bolignano D, Nistor I, et al. Glucose-lowering drugs in patients with chronic kidney disease: a narrative review on pharmacokinetic properties. Nephrol Dial Transplant. 2013;29(7):1284-1300.

26. Lu CH, Chang CC, Chuang LM, et al. Double-blind, randomized, multicentre study of the efficacy and safety of gliclazide-modified release in the treatment of Chinese type 2 diabetic patients. Diabetes Obes Metab. 2006;8(2):184-191.

27. Perkovic V, Heerspink HL, Chalmers J, et al. Intensive glucose control improves kidney outcomes in patients with type 2 diabetes. Kidney Int. 2013;83(3):517-523.

28. Coelho S, Carrilho P, Inchaustegui L. Management of hyperglycaemia in type 2 diabetic patients with chronic kidney disease. Port J Nephrol Hypertens. 2013;27(2):91-100.

29. Zoungas S, Chalmers J, Kengne AP, et al. The efficacy of lowering glycated haemoglobin with a gliclazide modified release-based intensive glucose lowering regimen in the ADVANCE trial. Diabetes Res Clin Pract. 2010;89(2):126-133.

30. Zanchi A, Lehmann R, Philippe J. Antidiabetic drugs and kidney disease - recommendations of the Swiss Society for Endocrinology and Diabetology. Swiss Med Wkly. 2012;142:1-8.

31. Van de LaarFA, Lucassen PL, Akkermans RP, et al. $\alpha$-Glucosidase inhibitors for patients with type 2 diabetes: results from a Cochrane systematic review and meta-analysis. Diabetes Care. 2005;28(1):154-163.

32. Hanefeld M, Cagatay M, Petrowitsch T, et al. Acarbose reduces the risk for myocardial infarction in type 2 diabetic patients: meta-analysis of seven long-term studies. Eur Heart J. 2004;25(1):10-16.

33. Göke B. Improved glycemic control and lipid profile in a randomized study of pioglitazone compared with acarbose in patients with type 2 diabetes mellitus. Treat Endocrinol. 2002;1(5):329-336.

34. Segal P, Feig PU, Schernthaner G, et al. The efficacy and safety of miglitol therapy compared with glibenclamide in patients with NIDDM inadequately controlled by diet alone. Diabetes Care. 1997;20(5):687-691.

35. Van de Laar FA, Lucassen PL, Kemp J, et al. Is acarbose equivalent to tolbutamide as first treatment for newly diagnosed type 2 diabetes in general practice? a randomised controlled trial. Diabetes Res Clin Pract. 2004;63(1):57-65

36. Dicker D. DPP-4 Inhibitors Impact on glycemic control and cardiovascular risk factors. Diabetes Care. 2011;34(2):S276-S278.

37. Chan JCN, Scott R, Arjona Ferreira JC, et al. Safety and efficacy of sitagliptin in patients with type 2 diabetes and chronic renal insufficiency. Diabetes Obes Metab. 2008;10(7):545-555.

38. Abe M, Okada K, Soma, M. Antidiabetic agents in patients with chronic kidney disease and end-stage renal disease on dialysis: metabolism and clinical practice. Curr Drug Metab. 2011;12(1):57-69.

39. Ohkubo Y, Kishikawa H, Araki E, et al. Intensive insulin therapy prevents the progression of diabetic microvascular complications in Japanese patients with non-insulin-dependent diabetes mellitus: a randomized prospective 6-year study. Diabetes Res Clin Pract. 1995; 28(2):103-117.
40. Zaman Huri H, Lee CL. Drug-related problems in type 2 diabetes mellitus patients with dyslipidemia. BMC Public Health. 2013;13:1192.

41. Schernthaner G, Ritz E, Schernthaner GH. Strict glycaemic control in diabetic patients with CKD or ESRD: beneficial or deadly? Nephrol Dial Transplant. 2010;25(7):2044-2047.

42. Speeckaert M, Van Biesen W, Delanghe J, et al. Are there better alternatives than haemoglobin A1c to estimate glycaemic control in the chronic kidney disease population? Nephrol Dial Transplant. 2014;0:1-11.

43. Hirst JA, Farmer AJ, Dyar A, Lung TWC, Stevens RJ. Estimating the effect of sulfonylurea on HbA1c in diabetes: a systematic review and meta-analysis. Diabetologia. 2013;56(5):973-984.

44. Ahmad NS, Islahudin F, Paraidathathu T. Factors associated with good glycemic control among patients with type 2 diabetes mellitus. J Diabetes Investig. 2013;5:563-569.

45. Cook MN, Girman CJ, Stein PP, Alexander CM. Initial monotherapy with either metformin or sulphonylureas often fails to achieve or maintain current glycaemic goals in patients with type 2 diabetes in UK primary care. Diabet Med. 2007;24(4):350-358.

46. Adham M, Froelicher ES, Batieha A, Ajlouni K. Glycaemic control and its associated factors in type 2 diabetic patients in Amman, Jordan. East Mediterr Health J. 2010;16(7):732-739.

47. Benoit SR, Fleming R, Philis-Tsimikas A, Ji M. Predictors of glycemic control among patients with Type 2 diabetes: a longitudinal study. $B M C$ Public Health. 2005;5(1):36-44.

48. Goudswaard AN, Stolk RP, Zuithoff P, Rutten GE. Patient characteristics do not predict poor glycaemic control in type 2 diabetes patients treated in primary care. Eur J Epidemiol. 2004;19(6):541-545.

49. Khattab M, Khader YS, Al-Khawaldeh A, Ajlouni K. Factors associated with poor glycemic control among patients with type 2 diabetes. J Diabetes Complications. 2010;24(2):84-89.

50. Wallace TM, Matthews DR. Poor glycaemic control in type 2 diabetes: a conspiracy of disease, suboptimal therapy and attitude. QJ Med. 2000; 93(6):369-374.

51. Adejumo BI, Dimkpa U, Ewenighi CO, et al. The Incidence of Anemia and the Impact of Poor Glycemic Control in Type-2 Diabetic Patients with Renal Insufficiency. J Biol Agric Healthcare. 2013;3(13): 130-136.

52. Sanal TS, Nair NS, Adhikari P. Factors associated with poor control of type 2 diabetes mellitus: a systematic review and meta-analysis. J Diabetol. 2011;3:1-10.

53. Longo-Mbenza B, Muaka MM, Mbenza G, et al. Risk factors of poor control of HBA1c and diabetic retinopathy: paradox with insulin therapy and high values of HDL in African diabetic patients. Int $J$ Diabetes Metab. 2008;16:69-78.

54. Mafauzy M. Diabetes control and complications in public hospitals in Malaysia. Med J Malaysia. 2006;61(4):477-483.

55. Mastura I, Chew BH, Lee PY, Cheong AT, Ghazali S. Control and treatment profiles of 70,889 adult type 2 diabetes mellitus patients in Malaysia - a cross sectional survey in 2009. Int J Collab Res Intern Med Public Health. 2011;3:98-113.

56. Inaba M, Okuno S, Kumeda Y, et al. Glycated albumin is a better glycemic indicator than glycated hemoglobin values in hemodialysis patients with diabetes: effect of anemia and erythropoietin injection. J Am Soc Nephrol. 2007;18(3):896-903.

57. Ng JM, Cooke M, Bhandari S, et al. The effect of iron and erythropoietin treatment on the $\mathrm{A} 1 \mathrm{C}$ of patients with diabetes and chronic kidney disease. Diabetes Care. 2010;33(11):2310-2313.

58. Jasik M, Kasperska-Dworak A, Czyżyk A. Effect of nifedipine, captopril and prazosin on secretory function of pancreatic $\beta$-cells in hypertensive patients with type-2 (non-insulin-dependent) diabetes and in hypertensive non-diabetics. Diabetes Res Clin Pract. 1996;33(1):59-66.

59. Dogan A, Yarlioglues M, Kaya MG, et al. Effect of long-term and high-dose allopurinol therapy on endothelial function in normotensive diabetic patients. Blood Press. 2011;20(3):182-187.

60. Mácsai E. Cardiovascular biomarkers in diabetic nephropathy (Doctoral dissertation, Semmelweis University, Hungary). Available from: http://phd.semmelweis.hu/mwp/phd_live/vedes/export/ macsaiemilia.e.pdf; 2013. 
Drug Design, Development and Therapy

Dovepress

\section{Publish your work in this journal}

Drug Design, Development and Therapy is an international, peerreviewed open-access journal that spans the spectrum of drug design and development through to clinical applications. Clinical outcomes, patient safety, and programs for the development and effective, safe, and sustained use of medicines are a feature of the journal, which

has also been accepted for indexing on PubMed Central. The manuscript management system is completely online and includes a very quick and fair peer-review system, which is all easy to use. Visit http://www.dovepress.com/testimonials.php to read real quotes from published authors.

Submit your manuscript here: http://www.dovepress.com/drug-design-development-and-therapy-journal 